\title{
Influencing Connected Legislators
}

\author{
Marco Battaglini \\ Cornell University and Einaudi Institute for Economics and Finance
}

Eleonora Patacchini

Cornell University

\begin{abstract}
This paper studies how interest groups allocate campaign contributions when congressmen are connected by social ties. We establish conditions for the existence of a unique Nash equilibrium in pure strategies for the contribution game and characterize the associated allocation of the interest groups' moneys. While the allocations are generally complex functions of the environment (the voting function, the legislators' preferences, and the social network topology), they are simple, monotonically increasing functions of the respective legislators' Katz-Bonacich centralities. Using data on the 109th-113th Congresses and on congressmen's alumni connections, we estimate the model and find evidence supporting its predictions.
\end{abstract}

\section{Introduction}

There is a large theoretical and empirical literature studying interest groups' influences on congressmen. This literature aims to derive and test predic-

For useful comments and discussions we thank Gregory Besharov, Tim Besley, Stephen Coate, Chris Cotton, Quoc-Anh Do, David Easley, Panle Jia Barwick, Francesca Molinari, Edoardo Rainone, Yves Zenou, and seminar participants at Caltech, Cornell, the European University Institute, Penn State, Pompeu Fabra, Queen Mary, London Business School, London School of Economics, Simon Business School, the 2016 Warwick political economy conference in Venice, and the 13th Center for Studies in Economics and Finance-Innocenzo Gasparini Institute for Economic Research Symposium on Economics and Institutions. We thank Angela Cools, Liyuan Cui, Valerio Leone Sciabolazza, Tianyi Li, Derek Lougee, and Sida Peng for outstanding research assistance. Data are provided as supplementary material online.

Electronically published October 30, 2018

[ Journal of Political Economy, 2018, vol. 126, no. 6]

(c) 2018 by The University of Chicago. All rights reserved. 0022-3808/2018/12606-0002 $\$ 10.00$ 
tions about interest groups' activities, starting with the assumption that congressmen are self-interested, individualistic utility maximizers. However, a long tradition in political science notes that treating legislators as solely self-interested individuals may be reductive, because it ignores deep connections of friendship, respect, and patronage that transcend partisan or ideological divisions. ${ }^{1}$ Recent work has creatively used a variety of data sources and methodologies to map legislators' social ties and show that these connections can help explain legislative success (Fowler 2006; Cho and Fowler 2010) and voting behavior (Arnold, Deen, and Patterson 2000; Masket 2008; Cohen and Malloy 2014; Harmon, Fisman, and Kamenica 2018) and may provide insights on congressional power centers (Porter et al. 2005; Zhang et al. 2008). For the most part, however, social connections among legislators have been ignored by the literature on interest groups. If interpersonal relations truly play a role in legislators' behavior, then we should expect them to play a role in how interest groups allocate resources among legislators.

In this paper, we present a new theory of campaign contributions in which legislators care about how other legislators in their social network behave. Even for realistically complex networks, our theory provides sharp predictions on how the interest groups allocate their resources on the basis of social network topology. We then use data from the 109th-113th Congresses to estimate the model. We find evidence that the measures of centrality suggested by our theory have a significant influence on the spending decisions of political action committees (PACs).

In our model, $n$ legislators vote to pass or reject a policy. Legislators care about the policy outcome but also care about the resources they can obtain from interest groups and about the behavior of other legislators to whom they are socially tied. We assume that legislators like to receive resources from interest groups (e.g., because these resources increase the likelihood of being reelected) ; ${ }^{2}$ they also like to vote for the option that they think is chosen by their friends. Social ties are represented by a network matrix whose generic element $g_{i j}$ represents the intensity of the influence of congressman $j$ on $i$. Two interest groups compete for the legislators' votes. Interest group $A$ aims to maximize the share of legislators who vote for a given policy; interest group $B$ aims for the opposite result. Each interest group has a given budget and can commit to offer payments to the legis-

\footnotetext{
${ }^{1}$ See, among others, Eulau (1962), Baker (1980), and Caldeira, Clark, and Patterson (1993). Among early quantitative studies of legislators' social interactions, see Rice (1927, 1928), Routt (1938), Patterson (1959), and Matthews and Stimson (1975). For historical discussions, see, e.g., Truman (1951), Bailey and Samuel (1952), and Clapp (1963).

${ }_{2}$ While it is useful to think of the interest groups' resources as money, this does not need to be the case. An example of a nonmonetary resource is information that the group can provide to the legislator.
} 
lators that are contingent on the legislators' votes; the legislators cast their ballots after observing the offers. We establish the conditions for the existence of a unique pure strategy Nash equilibrium of this game and characterize the associated equilibrium allocation of resources.

Perhaps unsurprisingly, we find that the allocation of the interest groups' moneys is generally a complex function of the voting rule, the legislators' preferences for the policy, and the geometry of the social network. While this relationship can be characterized in closed form, in practice it may be hard to compute it exactly for large networks, creating a challenge for empirical analysis. However, we show that when legislators are office motivated or when their number is large, the relationship between network topology and allocation of resources is simple: the interest groups allocate their resources in a way that is proportional to the Katz-Bonacich measure of centrality, a well-known concept of centrality in network theory (see, e.g., Zenou 2015). ${ }^{3}$

We then estimate our model and test whether the legislators' Katz-Bonacich centralities are good predictors of PAC contributions. We construct social networks exploiting the idea that educational institutions provide a basis for social networks (see, among others, Cohen, Frazzini, and Malloy [2008], Fracassi and Tate [2012], Cohen and Malloy [2014], and Do, Lee, and Nguyen [2016]). We therefore construct social networks using the congressmen's alumni connections: two congressmen are connected if they graduated from the same institution within a given time window. This approach gives us a network that is exogenous by construction to the political process. We control for other potential confounding effects associated with school quality by adding school fixed effects.

Using our alumni network, we obtain consistent results that support our theory. We find that standard measures of centrality such as degree, betweenness, closeness, and eigenvalue centralities have little power in explaining PAC contributions when compared to the Katz-Bonacich centrality, the measure predicted by our theory. The relevance of the Katz-Bonacich centrality, moreover, is robust to many natural controls suggested by the previous literature on the determinants of PAC contributions: measures of members' relative "power" inside the house (i.e., chairmanship, seniority, membership in the majority party, participation in important committees such as Appropriations or Way and Means), the margins of victory in the legislators' elections (as a proxy for the competitiveness in the district), gender, party affiliation, legislators' ideologies, and Congress-specific effects (as captured by Congress fixed effects). We estimate that a one standard deviation increase in a legislator's Katz-Bonacich centrality induces an in-

\footnotetext{
${ }^{3}$ The exact relationship between the Katz-Bonacich measure of centrality and the resources of legislators can also be characterized in closed form, but it depends on the specific assumptions on the legislator's utility function.
} 
crease in interest groups' contributions that is roughly comparable to what a legislator would achieve by being a member of the party in the majority. Perhaps more importantly, adding information on network topology as suggested by the theory significantly improves the fit of the model compared with the alternative specification that ignores this information.

The intuition behind the result that Katz-Bonacich centrality is a sufficient statistic to determine the allocation of resources for a sufficiently large $n$ depends on the following simple observation: as $n$ increases, the equilibrium probability that a legislator is pivotal for the outcome converges to zero. As the preferences of the legislator for the legislative outcome become decreasingly important, the dominant factor becomes the social network (and the interest groups' moneys). At that point, only the Katz-Bonacich centrality matters (as opposed to other measures of centrality such as degree or betweenness that focus on different dimensions of the network topology). This result depends on the fact that Katz-Bonacich centrality captures the recursive nature of the legislators' social interactions in the network, a feature that has also been highlighted in other environments (Ballester, Calvó-Armengol, and Zenou 2006; Calvó-Armengol, Patacchini, and Zenou 2009).

Our work is related to three strands of literature that to date have had little overlap. First, it relates to the political science literature on social networks in Congress already mentioned above. In addition to providing a variety of approaches to describe the legislators' social networks, this literature has shown that legislators' social connections explain voting behavior (Arnold et al. 2000; Porter et al. 2005; Masket 2008; Ringe, Victor, and Gross 2013; Cohen and Malloy 2014; Harmon et al. 2018) and legislative success, as measured by successful amendments (Monsma 1966; Fowler 2006; Canen and Trebbi 2016) or the number of bills passed (Cho and Fowler 2010). These recent works follow an older (if less formal) tradition in political science (see, among others, Rice [1927, 1928], Routt [1938], and Eulau [1962]).

Our work is also connected to a large theoretical and empirical literature exploring how interest groups influence Congress. ${ }^{4}$ The theoretical literature has been characterized by two types of models: informative theories, in which interest groups influence legislators by providing information (Calvert 1985; Austen-Smith and Wright 1992; Austen-Smith 1995; Bennedsen and Feldmann 2002; Cotton 2012), and campaign contribution theories, in which interest groups influence legislators by providing resources (Denzau and Munger 1986; Snyder 1991; Groseclose and Snyder 1996; Persson 1998; Diermeier and Myerson 1999; Helpman and Persson

\footnotetext{
${ }^{4}$ See Austen-Smith (1992) and Grossman and Helpman (2001) for surveys of theoretical research and Ansolabehere, de Figueiredo, and Snyder (2003), Stratmann (2005), and de Figueredo and Richter (2014) for surveys of empirical research.
} 
2001; Baron 2006; Dekel, Jackson, and Wolinsky 2009). ${ }^{5}$ The empirical literature has studied the determinants of PACs' allocations of campaign contributions, documenting evidence of interest groups' strategic behavior consistent with the campaign contribution theories (Poole and Romer 1985; Snyder 1990; Grier and Munger 1991; Stratmann 1992; Romer and Snyder 1994; Ansolabehere and Snyder 1999). ${ }^{6}$ This literature, however, for the most part has ignored social networks in Congress and the impact that they may have on interest groups' activities.

Finally, our work is related to the general literature on networks, which has also studied related issues of policy intervention and marketing in networks. The seminal paper studying policy intervention in networks is Ballester et al. (2006), which was among the first to propose an economic model of how the removal of a "key player" influences individual behavior. Our work differs from this because interest groups alter the agents' payoffs by making contingent promises, but they do not affect the network topology. The issue of marketing in networks has been studied in the computer science literature by Domingos and Richardson (2001) and Richardson and Domingos (2002), who considered the problem of a monopolist attempting to influence customers by allocating a budget of marketing resources. ${ }^{7}$ The case of competitive influencers has been studied by Bharathi, Kempe, and Salek (2007), who extend a contagion model by Kempe, Kleinberg, and Tardos $(2005,2015)$. In these works, marketers identify nodes in a network to start a contagion process. Contagion models have been applied in the political science literature to study influence on legislators by Groenert (2010), Lever (2010), and Groll and Prummer (2016). These papers, however, do not provide microfoundations of the legislators' decisions, since they assume that legislators collectively decide according to an exogenous decision function and are influenced through mechanical contagion processes that do not account for legislators' incentives.

The remainder of this paper is organized as follows. Section II presents our model of legislative behavior and competitive interest groups' activities. In Section III, we study the equilibrium of this game and characterize

\footnotetext{
${ }^{5}$ Related but distinct literatures are the literatures studying the influence of the choice of a single policy maker and the direct acquisition of citizens' votes. For the first, see Stigler (1971), Grossman and Helpman (1994), Dixit (1996), Dixit, Grossman, and Helpman (1997), and Besley and Coate (2001), among others. For the second, see Buchanan and Tullock (1962), Anderson and Tollison (1990), Piketty (1994), Dal Bo (2007), and Dekel, Jackson, and Wolinsky (2008).

${ }^{6}$ More recent research has extended the analysis to behavior of lobbyists, uncovering evidence that they provide expertise and access (Blanes i Vidal, Draca, and Fons-Rosen 2012; Bertrand, Bombardini, and Trebbi 2014; Kang 2015; Kang and You 2017).

${ }^{7}$ In their model, which is not based on an explicit microfoundation of behavior, the key determinant of the monopolist's allocation is a measure of centrality called the "network effect," which for an undirected network coincides with the degree centrality, a measure that is not relevant in our theory and does not appear significant in our empirical analysis.
} 
the relationship between the legislators' preferences, the voting rule, the network topology, and the interest groups' resource allocations. Section IV brings the model to data, Section V presents extensions to the model, and Section VI presents conclusions.

\section{Model}

Consider a legislature with $n$ members who choose between one of two alternatives: a new policy, denoted by $A$, and a status quo policy, denoted by $B$. All members cast a vote for either $A$ or $B$ and the legislature deliberates according to a $q$-rule with a generic $q \in(1 / 2,1)$, such that new policy $A$ is chosen if it achieves a share $q$ of votes.

Two factors determine a legislator's choice. First, each legislator cares about whether the policy is approved or not. This is described by a parameter $v^{i}$ : the utility enjoyed by $i$ if $A$ is approved. Since $v^{i}$ can be either positive or negative, we can normalize the benefit of approving $B$ at zero.

Second, each legislator cares directly about the vote he casts. This reflects two facts: first, interest groups observe a legislator's actions and may choose to reward votes with monetary contributions; and second, a legislator is influenced by other legislators and derives utility from voting that depends on how his peers behave. We write legislator $i$ 's direct utility of voting for policy $p \in\{A, B\}$ as

$$
U^{i}(p)=\omega\left(s^{i}(p)\right)+\phi \sum_{j} g_{i, j} \chi_{j}(p)+\varepsilon_{p}^{i} .
$$

The first term in (1) is the utility of the interest groups' contributions: $s^{i}(p)$ is the sum of contributions pledged to $i$ in exchange for a vote for $p$ and $\omega(s)$ is the utility that legislator $i$ receives from contribution $s$. We assume $\omega(\cdot)$ is an increasing, concave, twice differentiable function with $\lim _{s \rightarrow 0} \omega^{\prime}(s)=\infty, \lim _{s \rightarrow \infty} \omega^{\prime}(s)=0$. The second term describes the social interaction effects. As in Ballester et al. (2006), the social network is described by an $n \times n$ matrix $G$ with generic element $g_{i, j}: \chi_{j}(p)$ is an indicator function equal to one if legislator $j$ votes for $p$ and zero otherwise, and $g_{i, j}$ measures the strength and sign of the social influence of legislator $j$ on legislator $i$. When $g_{i, j}>0, i$ 's preference for $A$ increases if $j$ votes for $A$; when $g_{i, j}<0, i$ 's preference for $A$ decreases if $j$ votes for $A$ : this latter effect may occur if $i$ perceives that voting as $j$ could be embarrassing if, for example, $j$ has taken positions that are unpopular in $i$ 's electoral district. We assume that $\Sigma_{i} g_{i, j}$ is the same for every $i$ and we normalize this sum to one. ${ }^{8}$

\footnotetext{
${ }^{8}$ When the $g_{i, j}$ 's are all nonnegative, the assumption that $\Sigma_{j} g_{i, j}=1$ can be interpreted as reflecting the fact that $i$ has a limited budget of attention that can be given to the behavior of other legislators. In this case, $g_{i, j}$ can be interpreted as the share of $i$ 's attention that is devoted to $j$.
} 
The final term in (1) represents other exogenous factors that may affect $i$ 's preference for or aversion to voting for $p$. We can set $\varepsilon_{B}^{i}=\varepsilon^{i}$, where $\varepsilon^{i}$ can be positive or negative, and normalize $\varepsilon_{A}^{i}$ to zero.

For future reference, we say that a legislator is office motivated if he does not care about the policy outcome (so $v^{i}=0$ ); we say that a legislator is policy motivated if he does care about the policy outcome (so $v^{i}>0$ or $\left.v^{i}<0\right){ }^{9}$

The key assumption in (1) is that legislators like to conform to the behavior of the members of their social circle. These types of preferences (in which the utility of an action depends on the other players' actions) are standard in the literature on social network externalities and have been applied to study social interactions in a variety of contexts (see, among others, Schelling [1973], Becker [1991], Glaeser, Sacerdote, and Scheinkman [1996], Becker and Murphy [2001], and Brock and Durlauf [2001]). They appear especially appropriate in the context of social networks in legislatures. Conformism in organizations is a phenomenon that has been well documented in the psychology literature (e.g., Asch 1951; Deutsch and Gerard 1955; Ross, Bierbrauer, and Hoffman 1976; Jones 1984) and, more specifically, in legislatures. Cohen and Malloy (2014) and Harmon et al. (2018) have recently shown that peers affect voting behavior in the US Senate and the European Parliament; in Section IV.B we show evidence that a similar phenomenon is true for the US Congress. On the theoretical front, various authors have proposed microfoundations of conformist preferences as in (1), rationalizing them as implications of the agents' quests for social status (see Akerlof 1980; Jones 1984; Bernheim 1994). ${ }^{10}$

Two interest groups, also denoted $A$ and $B$, attempt to influence the policy outcome. Interest group $A$ is interested in persuading as many legislators as possible to choose policy $A$; interest group $B$, instead, is interested in persuading the legislators to choose policy $B$. Each interest group is endowed with a budget $W$ and promises a contingent payment to each legislator who follows its recommendation. Specifically, interest group $A$ promises a vector of payments $\mathbf{s}_{A}=\left(s_{A}^{1}, \ldots, s_{A}^{n}\right)$ to the legislators,

\footnotetext{
${ }^{9}$ Besides being interesting in itself, the case of office-motivated legislators is important since most of the existing literature on "buying legislatures" has focused on this case. See, e.g., Groseclose and Snyder (1996), Banks (2000), and Dekel et al. (2009).

${ }^{10}$ In an alternative interpretation, $i$ may like to vote similarly to $j$ not because of conformism, but because he expects an act of reciprocity from $j$ in the future (i.e., that $j$ will vote similarly to $i$ on a bill that $i$ would like to pass) or because $i$ and $j$ are in a vote-trading equilibrium in which they exchange favors over time. The stronger the social compatibility between $i$ and $j$, the more we should expect these phenomena. For example, in the presence of multiple equilibria, cooperative vote-trading equilibria may be more focal if $i$ and $j$ went to school together. Indeed, Cohen and Malloy (2014) find that vote trading is more common among connected legislators. While providing an explicit microfoundation for these types of dynamic interactions goes beyond the scope of this paper, we note that (1) can be seen as a reduced-form version of these types of interactions.
} 
where $s_{A}^{i}$ is the payment received by legislator $i$ if he chooses $A$; similarly, interest group $B$ promises a vector of payments $\mathbf{s}_{B}=\left(s_{B}^{1}, \ldots, s_{B}^{n}\right)$ to the legislators, where $s_{B}^{i}$ is the payment received by legislator $i$ if he votes for $B .{ }^{11}$

We assume that the interest groups do not know with certainty the legislators' preferences and so are unable to perfectly forecast how payments affect their voting behavior. Specifically, we assume $\varepsilon^{i}$ is an independent, uniformly distributed variable with mean zero and density $\Psi>0$, whose realization is observed only by $i^{12}$ Let $\varphi_{i}$ be the probability that $i$ votes for $A$ and $\varphi=\left(\varphi_{i}\right)_{i=1}^{n}$ be the associated vector of probabilities. Moreover, let $q^{i}(\varphi)$ be legislator $i$ 's pivot probability, that is, the probability that a vote by $i$ for $A$ changes the outcome from $B$ to $A$ given $\varphi$. Legislator $i$ is willing to vote for $A$ if and only if

$$
E\left[U^{i}(B)-U^{i}(A)\right] \leq v^{i} q^{i}(\boldsymbol{\varphi}) .
$$

The right-hand side of (2) is the expected benefit of helping policy $A$ win: the utility of the policy $v^{i}$ times the probability that the vote is actually decisive in determining the outcome. The left-hand side is the implicit cost of voting for $A$ in terms of loss of monetary contributions, personal aversion, and "social" pressure. ${ }^{13}$ Naturally, we must have $\varphi_{i}=E\left(\chi_{i}(A)\right)$, so (2) can be rewritten as a condition on $s_{A}^{i}, s_{B}^{i}, \varphi$, and $\varepsilon^{i}$ only:

$$
\varepsilon^{i} \leq \omega\left(s_{A}^{i}\right)-\omega\left(s_{B}^{i}\right)+v^{i} q^{i}(\varphi)+\phi \sum_{j} g_{i, j}\left(2 \varphi_{j}-1\right) .
$$

In the following, we focus on environments in which for any feasible $s_{A}, s_{B}$ there is sufficient uncertainty that the probability of (3) is interior and so no interest group can be sure about a legislator's decision. Let $\bar{v}$ be the highest valuation in absolute value: $\bar{v}=\max _{i}\left|v^{i}\right|$. A sufficient condition for this to be true, which we will maintain throughout the paper, is the following.

Assumption 1. $\Psi(\bar{v}+\phi+\omega(2 W))<1 / 2$.

The important observation is that this condition is satisfied if $\Psi$ is sufficiently small, that is, if there is sufficient uncertainty on the legislators' preferences.

11 In Sec. V, we extend this basic model in various directions: we allow for more than two interest groups (Sec. V.B), we allow for asymmetric interest groups with different budgets (Sec. V.C), we consider alternative objective functions for the interest groups (Sec. V.D), we consider the case in which the legislators vote on multiple policies and interest groups have heterogeneous preferences on the policies (Sec. V.E), and we consider the case in which legislators can abstain from voting (Sec. V.F).

${ }_{12}$ Formally, therefore, $\varepsilon^{i}$ is uniformly distributed on $[-1 /(2 \Psi), 1 /(2 \Psi)]$.

${ }^{13}$ From $(1)$, we can see that $U^{i}(p)$ is a function of the actions of the other legislators, $x_{j}(p)$ for $j \neq i$. Since the agent does not know them, they are evaluated at their expected values: this is the reason we have an expectation in (2). Note, moreover, that $\varepsilon^{i}$ is known to the agent, so it enters (2) only as a parameter. 
A strategy for interest group $l$ is a probability distribution over the set of feasible transfers $S$, that is,

$$
S=\left\{s: \sum_{i} s^{i} \leq W, s^{i} \geq 0 \text { for } i=1, \ldots, n\right\} .
$$

A pair of strategies constitute a Nash equilibrium if they are mutually optimal: the strategy of interest group $A$ maximizes the expected number of legislators who adopt $A$ given $\varphi$ and interest group $B$ 's strategy; and the strategy of interest group $B$ minimizes the expected number of legislators who adopt $A$ given $\varphi$ and interest group $A$ 's strategy. In the remainder of the paper we focus on equilibria in pure strategies, that is, on pairs of vectors $\mathbf{s}_{A}, \mathbf{s}_{B}$ in $S \times S$ that are mutually optimal. Propositions 1 and 2 guarantee that a pure strategy equilibrium exists and is unique.

In the following pages we consider very complex networks that cannot be easily visualized. ${ }^{14}$ In these cases it is useful to define simple statistics that describe the position of an agent in the network. A standard measure in the theory of networks that will play an important role in the analysis below is Katz-Bonacich centrality (Bonacich 1987; Ballester et al. 2006; Bramoulle, Kranton, and D'Amours 2014). For a given network matrix $\hat{G}$, the vector of Katz-Bonacich centralities, if it exists, is defined as

$$
\mathbf{b}(\delta, \hat{G})=(I-\delta \hat{G})^{-1} \cdot \mathbf{1},
$$

where $\delta<1$ is a positive parameter that controls the rate of decay of the influence in indirect links, $I$ is the identity matrix, and $\mathbf{1}$ is a column vector of ones. The Katz-Bonacich centrality of legislator $i$ with respect to $\hat{G}$ and $\delta$ is the $i$ th entry of $\mathbf{b}(\delta, \hat{G})$. Katz-Bonacich centralities may not exist because the matrix $I-\delta \hat{G}$ may fail to be invertible. Invertibility is guaranteed for any $\hat{G}$ if $\delta$ is sufficiently small. For the reminder of the paper, a condition that guarantees that the relevant Katz-Bonacich centralities exist in our environment is the following:

Assumption 2. The matrix $I-2 \phi \Psi G$ is invertible and the associated Katz-Bonacich vector is positive: $(I-2 \phi \Psi G)^{-1} \cdot \mathbf{1}>0$.

Note that, as for assumption 1, this condition is satisfied if $\Psi$ and/ or $\phi$ is sufficiently small. ${ }^{15}$ We assume that the relevant Katz-Bonacich

\footnotetext{
${ }^{14}$ In Sec. IV, we apply the model to the US Congress. In this case, the network has over 400 nodes per Congress (the congressmen) and thousands of links.

${ }^{15}$ If we assume a positive matrix of social interactions, i.e., $g_{i, j}>0$ for $i, j \in N$, then a sufficient condition for assumption 2 is the condition assumed by Ballester et al. (2006): $\Psi<1 /\left[2 \phi \mu_{1}(G)\right]$, where $\mu_{1}(G)$ is the largest eigenvalue of $G$ (see also Bramoulle et al. 2014). This condition guarantees that $(I-2 \phi \Psi G)^{-1}$ exists and it is positive, which implies $(I-2 \phi \Psi G)^{-1} \cdot 1>0$. However, assumption 2 is weaker for two reasons: first, it does not require $g_{i, j}>0$, allowing positive and negative social interactions; second, it requires only $(I-2 \phi \Psi G)^{-1} \cdot 1>0$ and not the stronger condition that the entire matrix $(I-2 \phi \Psi G)^{-1}$ is positive.
} 
centralities $(I-2 \phi \Psi G)^{-1} \cdot \mathbf{1}$ are positive for simplicity and because it appears to be the most plausible case. In the context of our model, a vector $(I-2 \phi \Psi G)^{-1} \cdot 1$ with negative components, that is, a negative KatzBonacich centrality for some $i$, corresponds to the case in which some legislator $i$ generates such negative externalities that a marginal increase in the probability that $i$ votes for $A$ induces a reduction in the expected plurality for $A$.

In general, it is difficult to compare the Katz-Bonacich centralities in networks with different $n$ because an increase in the number of agents may completely change the topology of the network. However, the comparison is straightforward when the agents in the networks can be classified into a finite number of types, each comprising a given fraction of the population. We say that two legislators $i$ and $j$ have the same type if they have the same preferences, $v^{i}=v^{j}$, and if they interact in the same way with the other legislators, so $g_{i, k}=g_{j, k}$ and $g_{k, i}=g_{k, j}$ for all $k=1, \ldots, n$. As we formally prove in lemma 3.1, presented in the online appendix, in this case each agent of the same type has the same centrality and, more importantly, the centralities depend only on the share of the population of each type.$^{16}$ In the following analysis we assume that there is at most a finite number $m$ of types of legislators. ${ }^{17}$

\section{Equilibrium Contributions}

The game described in the previous section has two stages. In the first stage, the influence stage, the interest groups simultaneously promise monetary contributions to the legislators contingent on their votes. In the second stage, the voting stage, the legislators simultaneously choose how to vote given the interest groups' promises. We can solve this game by backward induction: first, we solve the voting stage, taking as given the allocation of transfers; second, we solve the influence stage, given the continuation value for the voting stage.

\section{A. The Voting Stage}

Each legislator chooses his ballot on the basis of his preferences, the monetary promises, and his expectations of the other legislators' behav-

\footnotetext{
${ }^{16}$ The requirement that two agents $i$ and $j$ of the same type have $v^{i}=v^{j}$ is irrelevant when the centrality measure is the Katz-Bonacich, since this centrality does not depend on the agents' preferences. When we have policy-motivated legislators, however, the relevant centrality measure is the modified Katz-Bonacich centrality (defined in [15]) that depends on the agents' $v^{i}$ 's.

${ }^{17}$ Naturally this assumption is without loss of generality if $n$ is finite, and it will play a role only when we consider sequences of economies as $n \rightarrow \infty$.
} 
ior. Because of this, the voting probabilities must be jointly determined in equilibrium and no legislator can be treated in isolation. From (3) we have that the legislators' probabilities of choosing $A, \varphi$, are characterized by the following nonlinear system:

$$
\left(\begin{array}{c}
\varphi_{1} \\
\cdots \\
\varphi_{n}
\end{array}\right)=\left(\begin{array}{c}
\frac{1}{2}+\Psi\left(\omega\left(s_{A}^{1}\right)-\omega\left(s_{B}^{1}\right)+v^{1} q^{1}(\boldsymbol{\varphi})+\phi \sum_{j} g_{1, j}\left(2 \varphi_{j}-1\right)\right) \\
\cdots \\
\frac{1}{2}+\Psi\left(\omega\left(s_{A}^{n}\right)-\omega\left(s_{B}^{n}\right)+v^{n} q^{n}(\boldsymbol{\varphi})+\phi \sum_{j} g_{n, j}\left(2 \boldsymbol{\varphi}_{j}-1\right)\right)
\end{array}\right) .
$$

For any $\mathbf{s}=\mathbf{s}_{A}, \mathbf{s}_{B}$, the system of equations (5) defines a function $T(\mathbf{s}, \varphi)$ that maps the vector of probabilities $\varphi$ to itself. A voting equilibrium is a fixed point $\boldsymbol{\varphi}(\mathbf{s})=T(\mathbf{s}, \boldsymbol{\varphi}(\mathbf{s}))$ of this correspondence. Since $T$ is continuous in $\varphi$ from $[0,1]^{n}$ to itself, Brouwer's fixed-point theorem implies that an equilibrium exists for any pair $\mathbf{s}_{A}, \mathbf{s}_{B}$ of transfers by the interest groups.

In general, (5) may admit multiple solutions and the solution may not be well behaved in the monetary transfers (as, e.g., multiplicity may induce $\boldsymbol{\varphi}$ to be discontinuous in $\mathbf{s}_{A}, \mathbf{s}_{B}$ ). The following result shows that, indeed, (5) admits a unique, well-behaved solution when there is sufficient uncertainty on the legislators' types.

Lemma 1. There is a $\Psi^{*}$ such that for any $\Psi \leq \Psi^{*}$ the vector of equilibrium probabilities $\boldsymbol{\varphi}(\mathbf{s})=\left\{\boldsymbol{\varphi}_{1}(s), \ldots, \boldsymbol{\varphi}_{n}(s)\right\}$ solving (5) is unique. Moreover, the sum of the equilibrium probabilities $\sum_{i} \varphi_{i}(s)$ is increasing, differentiable in $s_{A}^{i}$ (respectively, decreasing and differentiable in $s_{B}^{i}$ ) for all $i$, and concave in $\mathbf{s}_{A}$ (respectively, convex in $\mathbf{s}_{B}$ ).

To see the intuition of this result, consider first the case in which legislators are office motivated (i.e., $v^{j}=0$ for all $j$ ). In this case, (5) is a linear system with a unique solution $\varphi^{*}$. Consider now the marginal effect of an increase in $s_{A}^{i}$. Differentiating (5), we obtain

$$
\partial \varphi_{j}^{*} / \partial s_{A}^{i}=\Psi\left[\omega^{\prime}\left(s_{A}^{i}\right) \cdot 1_{j, i}+2 \phi \sum_{l} g_{j, l} \cdot \partial \varphi_{l}^{*} / \partial s_{A}^{i}\right],
$$

where $1_{j, i}$ is an indicator function equal to one when $j=i$ and zero otherwise. The first term in the brackets is the direct effect of an increase in $s_{A}^{i}$ : it induces a marginal change in legislator $j$ 's utility of $\omega^{\prime}\left(s_{A}^{i}\right)$ if $j=i$, and zero otherwise. The second term is the indirect network effect: the change in $i$ 's behavior induces a change in legislator $l$ 's behavior $\partial \varphi_{l}^{*} / \partial s_{A}^{i}$, which in turn affects $j$ 's behavior in a recursive fashion. The system of equations (6) can be rewritten in matrix form as $D_{i}[\varphi]=$ $\Psi\left[D_{i}[\boldsymbol{\omega}]+2 \phi G \cdot D_{i}[\boldsymbol{\varphi}]\right]$, where $D_{i}[\boldsymbol{\varphi}]$ and $D_{i}[\boldsymbol{\omega}]$ are the Jacobians of, re- 
spectively, $\varphi$ and $\omega$ with respect to $s_{A}^{i}$. By assumption $2,[I-2 \Psi \phi \cdot G]^{-1}$ exists, so we can write

$$
D_{i}[\boldsymbol{\varphi}]=\Psi[I-2 \Psi \phi \cdot G]^{-1} D_{i}[\boldsymbol{\omega}] .
$$

Since $D_{i}[\omega]=\left(0, \ldots, 0, \partial \omega\left(s_{A}^{i}\right) / \partial s_{A}^{i}, \ldots, 0\right)^{T}$, we have that

$$
\sum_{j} \partial \varphi_{j}^{*} / \partial s_{A}^{i}=\sum_{j} m_{j, i} \omega^{\prime}\left(s_{A}^{i}\right) \quad \text { and } \quad \sum_{j} \partial^{2} \varphi_{j}^{*}(\mathbf{s}) / \partial^{2} s_{A}^{i}=\sum_{j} m_{j, i} \omega^{\prime \prime}\left(s_{A}^{i}\right),
$$

where $m_{j, i}$ is the $j i$ th element of $[I-2 \Psi \phi G]^{-1}$. As it is easy to verify, as $\Psi \rightarrow 0, \Sigma_{j} m_{j, i} \rightarrow 1$ for any $i$; so for a sufficiently small $\Psi$ we have $\Sigma_{j} m_{j, i}>$ 0 , implying $\Sigma_{j} m_{j, i} \omega^{\prime}\left(s_{A}^{i}\right)>0$ and $\Sigma_{j} m_{j, i} \omega^{\prime \prime}\left(s_{A}^{i}\right)<0$. Voting probabilities are therefore unique, increasing, and concave in $s_{A}^{i}$ for a sufficiently small $\Psi .{ }^{18}$ A similar argument establishes the respective properties for $s_{B}^{i}$.

With policy-motivated legislators, the analysis is slightly more complicated because we need to take into account the pivot probabilities, which are nonlinear functions in $\varphi$. Lemma 1 shows that when there is sufficiently high uncertainty on the legislators' preferences, these nonlinearities are not problematic because the pivot probabilities are sufficiently insensitive to changes in the monetary allocations.

In the following, we will maintain the assumption that $\Psi$ is sufficiently small that the properties described in lemma 1 are satisfied:

Assumption 3. There is sufficient uncertainty on the legislators' preferences so that $\sum_{i} \varphi_{i}(s)$ is increasing, differentiable in $s_{A}^{i}$ (respectively, decreasing and differentiable in $s_{B}^{i}$ ) for all $i$, and concave in $\mathbf{s}_{A}$ (respectively, convex in $\mathbf{s}_{B}$ ).

Figure 1 illustrates the system (5) in a simple "star" network example in which there is a central legislator, say legislator 0 , who is connected to all other legislators and $n-1$ peripheral legislators $j=1, \ldots, 4$, who in turn are connected only to the central legislator. ${ }^{19}$ The symmetric structure implies that the probabilities of $j=1, \ldots, 4$ are equal, and so (5) collapses to two equations in two unknowns, $\varphi_{0}$ and $\varphi_{j}=\varphi_{-0}$ for all $j=1, \ldots, 4$. Assuming that legislators have the same logarithmic utility $\omega_{i}(s)=\beta_{0} \log (s)$, the voting probabilities are characterized by

$$
\begin{aligned}
\varphi_{0}= & \frac{1}{2}+\Psi \cdot\left[\log \left(s_{A}^{0} / s_{B}^{0}\right)+4 \phi\left(2 \varphi_{-0}-1\right)+6 \varphi_{-0}^{2}\left(1-\varphi_{-0}\right)^{2}\right], \\
\varphi_{-0}= & \frac{1}{2}+\Psi \cdot\left[\log \left(s_{A}^{-0} / s_{B}^{-0}\right)+\phi\left(2 \varphi_{0}-1\right)+3 \varphi_{0} \varphi_{-0}\left(1-\varphi_{-0}\right)^{2}\right. \\
& \left.+3\left(1-\varphi_{0}\right)\left(1-\varphi_{-0}\right) \varphi_{-0}^{2}\right],
\end{aligned}
$$

${ }^{18}$ When $g_{i, j}>0$ for all $i, j$, we have that $m_{i, j}>0$ for all $i, j$ when $\Psi$ is sufficiently small. When $g_{i, j}$ are not necessarily all positive, we may have some $m_{i, j}<0$; but we necessarily have $\sum_{i} m_{i, j}>0$, since the elements on the diagonal converge to one and the elements off the diagonal converge to zero as $\Psi \rightarrow 0$.

${ }^{19}$ Formally, $g_{0, j}=g_{j, 0}=1$ for all $j$ and $g_{i, j}=0$ if neither $i$ nor $j$ is equal to zero. 

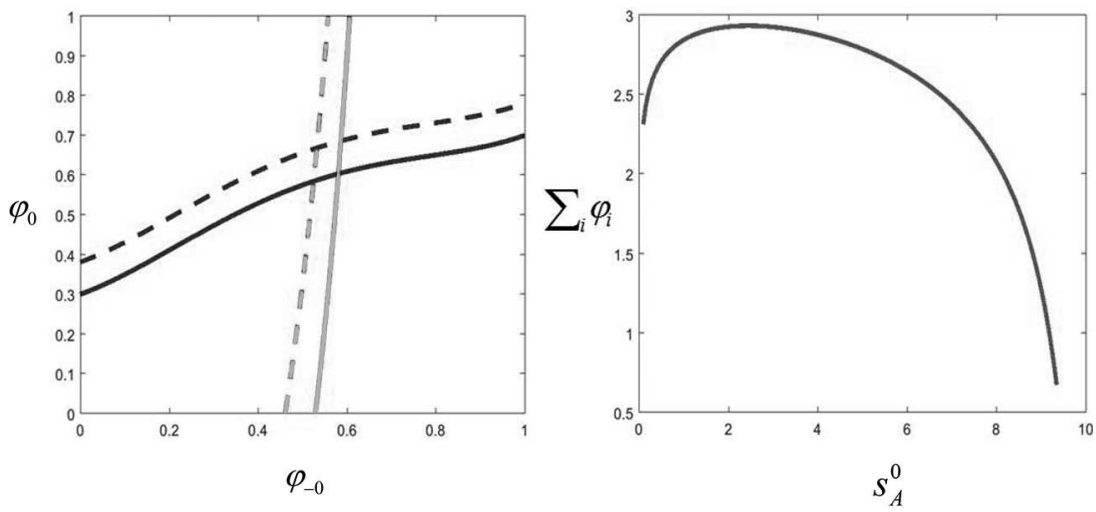

FIG. 1.-The flatter lines in the left panel represent the reaction function of agent 0 to $\varphi_{-0}$. The steeper lines are the reaction functions of all the other agents to $\varphi_{0}$. The intersections of the reaction functions correspond to voting equilibria for different allocations of the campaign contributions. The right panel illustrates the number of votes as a function of $s_{A}^{0}$ (adjusting $s_{A}^{-0}$ to satisfy the budget condition). Color version available as an online enhancement.

where $s_{j}^{0}$ (respectively, $s_{j}^{-0}$ ) is the transfer by interest group $j$ to legislator 0 (respectively, -0 ). The solid lines in the left panel of figure 1 illustrate the legislators' reaction functions in the case in which the interest group allocates $W=10$ evenly:20 their intersection is a solution of (8) and a voting equilibrium. Given $B$ 's promise $\mathbf{s}_{B}$, interest group $A$ can control the equilibrium probabilities by changing $\mathbf{s}_{A}$. The dashed lines in figure 1 illustrate the effect of a redistribution by $A$ of money on $\varphi=\left(\varphi_{0}, \varphi_{-0}\right)$ from the initial even distribution $\left(s^{i}=2\right.$ for all $\left.i\right)$ to a distribution that favors $i=0: s_{A}^{0}=3, s_{A}^{j}=s_{A}^{-0}=7 / 4$ for $j=1, \ldots, 4$. Despite the fact that each legislator does not directly care about the transfers sent to the other players, his behavior is indirectly affected by the transfers to the other legislators since these transfers affect behavior in his social network. Given the symmetry of this example, $s_{A}^{-0}$ is automatically given as a function of $s_{A}^{0}$ by the budget condition $s_{A}^{-0}=\left(10-s_{A}^{0}\right) / 4$. The right panel of figure 1 illustrates interest group $A$ 's objective function as a function of $s_{A}^{0}$ keeping $s_{B}^{0}, s_{B}^{-0}$ constant at $(2,2) .{ }^{21}$

\section{B. The Influence Stage}

We can now turn to the interest groups' problems in the first stage. Interest group $A$ solves

${ }^{20}$ Specifically, in the example of fig. 1, we assume $\beta_{0}=1, \phi=0.25, \Psi=0.2, q=1 / 2$, and $v^{i}=1$ for all $i$.

${ }^{21}$ Naturally, in this case $\sum_{\varphi_{j}}$ is not monotonically increasing in $s_{A}^{0}$ since we are imposing the budget condition $s_{A}^{-0}=\left(10-s_{A}^{0}\right) / 4$. 


$$
\max _{\mathbf{s}_{A} \in S}\left\{\sum_{i}\left[\boldsymbol{\varphi}_{i}\left(\mathbf{s}_{A}, \mathbf{s}_{B}\right)\right]\right\}
$$

taking $\mathbf{s}_{B}$ as given. Interest group $B$ 's problem is the mirror image of $A$ 's problem, as it attempts to minimize the objective function of (9) taking $s_{A}$ as given.

Under assumption 3, (9) is a standard maximization program. This implies that $A$ 's optimal choice is uniquely defined and is a continuous function in $s_{B}$ (and symmetrically $B$ 's reaction function is a continuous function of $s_{A}$ ). The Brouwer's fixed-point theorem implies that a Nash equilibrium in pure strategies exists. The equilibrium solution, moreover, must satisfy the first-order condition:

$\sum_{j} \partial \varphi_{j}\left(\mathbf{s}_{A}, \mathbf{s}_{B}\right) / \partial s_{l}^{i}=\lambda_{l}$ and $\sum_{j=1}^{n} s_{l}^{j}=W$ for $i=1, \ldots, n, l=A, B$,

where $\lambda_{l}$ is the Lagrangian multiplier associated with the budget constraints $\sum_{i} s_{l}^{i} \leq W$ in interest group $l$ 's problem. By a standard argument we can show that it must be that $A$ and $B$ 's problems have the same Lagrangian multipliers $\lambda_{A}=\lambda_{B}=\lambda_{*}{ }^{22}$

To discuss the implications of (10) intuitively, we will first consider the case in which legislators are office motivated. We then generalize the results to the case of legislators that are policy motivated.

\section{Office-Motivated Legislators}

We can rewrite the necessary and sufficient condition with respect to $s_{A}^{i}$, (10), in matrix form as

$$
D_{i}[\boldsymbol{\varphi}]^{T} \cdot \mathbf{1}=\lambda_{*}
$$

where $D_{i}[\boldsymbol{\varphi}]^{T}=\left(\partial \boldsymbol{\varphi}_{1}^{*} / \partial s_{A}^{i}, \ldots, \partial \varphi_{n}^{*} / \partial s_{A}^{i}\right)$ and $\mathbf{1}$ is an $n$-dimensional column vector of ones. Using (7), we have

$$
\begin{aligned}
D_{i}[\boldsymbol{\varphi}]^{T} \cdot \mathbf{1} & =\Psi \cdot D_{i}[\boldsymbol{\omega}]^{T} \cdot\left(I-\phi^{*} \cdot G^{T}\right)^{-1} \cdot \mathbf{1}=\lambda_{*} \\
& \Rightarrow D_{i}[\boldsymbol{\omega}]^{T} \cdot \mathbf{b}\left(\phi^{*}, G^{T}\right)=\lambda_{*} / \Psi
\end{aligned}
$$

where $\phi^{*}=2 \Psi \phi$, and for the last equality we used the definition of the vector of Katz-Bonacich centralities (4). Recall that $D_{i}[\omega]$ is a vector of zeros except for its $i$ th element, which is equal to $\omega^{\prime}\left(s_{*}^{i}\right)$. We can therefore write our necessary and sufficient condition (10) as

${ }^{22}$ As discussed in greater detail in the proof of propositions 1 and 2, if $\lambda_{A}>\lambda_{B}$ (respectively, $\lambda_{A}<\lambda_{B}$ ), then (10) would imply $\omega^{\prime}\left(s_{A}^{i}\right)>\omega^{\prime}\left(s_{B}^{i}\right)$ (respectively, $\omega^{\prime}\left(s_{A}^{i}\right)<\omega^{\prime}\left(s_{B}^{i}\right)$ ) for any $i$, implying $\Sigma s_{B}^{i}>\sum s_{A}^{i}=W$ (respectively, $\left.\Sigma s_{A}^{i}>\sum s_{B}^{i}=W\right)$, a contradiction. 


$$
b_{i}\left(\phi^{*}, G^{T}\right) \cdot \omega^{\prime}\left(s_{*}^{i}\right)=\lambda_{*} \quad \text { for } i=1, \ldots, n,
$$

where, without loss of generality, we incorporate the constant $\Psi$ in the Lagrangian multiplier $\lambda_{*}$.

The necessary and sufficient condition (12) shows the determinants of the interest group's monetary allocation. The interest group chooses $s_{*}^{i}$ to equalize the marginal cost of resources and their marginal benefit. The marginal cost is measured by the Lagrangian multiplier $\lambda_{*}$ of (9). The marginal benefit is measured by the increase in expected votes for $A$. Equation (12) makes clear that, because of network effects, the direct benefit of a transfer to $i$ is magnified by a factor that is exactly equal to $b_{i}\left(\phi^{*}, G^{T}\right)$, the Katz-Bonacich centrality of $i$ in $G^{T}$ with coefficient $\phi^{*}$.

An immediate implication of (12) is the following result.

Proposition 1. With office-motivated legislators, there is a unique equilibrium in which the interest groups choose the same vector of transfers $s_{*}$. The vector $s_{*}$ solves the problem

$$
\max _{\mathbf{s} \in S}\left\{\sum_{j} b_{j}\left(\phi^{*}, G^{T}\right) \cdot \omega_{j}\left(s^{j}\right)\right\},
$$

where $b_{j}\left(\phi^{*}, G^{T}\right)$ is the Katz-Bonacich centrality measure of $i$ in $G^{T}$ with coefficient $\phi^{*}=2 \Psi \phi$.

If we assume that the utility from money is logarithmic, then the transfer promised to legislator $i$ is exactly proportional to his Katz-Bonacich centrality, with a factor of proportionality that depends on the inverse of the shadow cost of resources $\lambda^{*}$. In general, (13) shows that money is chosen in order to maximize a weighted sum of the legislators' monetary utilities, where the weights are exactly equal to the respective Katz-Bonacich centrality measures.

\section{Policy-Motivated Legislators}

When legislators are not purely office motivated, the analysis is complicated by the fact that a marginal increase in a payment $s_{A}^{i}$ has an additional effect on voting probabilities that does not exist with exclusively officemotivated legislators. By affecting the voting probabilities of all players, an increase in $s_{A}^{i}$ changes the pivot probabilities $q(\varphi)=\left(q^{i}(\varphi)\right)_{i=1}^{n}$. This effect is irrelevant with office-motivated legislators because they do not care about the policy outcome.

Taking this into account, the analysis proceeds in the same way as above assuming $\Psi$ sufficiently small so that the objective function of (9) is concave. Concavity and the symmetry of the two groups' problems imply that the equilibrium is unique and symmetric with $s_{A}=s_{B}=s_{*}$. Given this, (5) becomes the system 


$$
\left(\begin{array}{c}
\varphi_{1}^{*} \\
\cdots \\
\varphi_{n}^{*}
\end{array}\right)=\left(\begin{array}{c}
\frac{1}{2}+\Psi\left(v^{1} q^{1}(\boldsymbol{\varphi})+\phi \sum_{j} g_{1, j}\left(2 \varphi_{j}^{*}-1\right)\right) \\
\cdots \\
\frac{1}{2}+\Psi\left(v^{n} q^{n}(\boldsymbol{\varphi})+\phi \sum_{j} g_{n, j}\left(2 \varphi_{j}^{*}-1\right)\right)
\end{array}\right)
$$

This system admits a solution that depends only on exogenous variables $\phi, G, \Psi$, and $\left(v^{i}\right)_{i=1}^{n}$. The equilibrium vector $\varphi^{*}=\left(\varphi_{1}^{*}, \ldots, \varphi_{n}^{*}\right)$ can therefore be taken as a function of only the primitives of the model.

Let $D \mathbf{q}_{*}$ be the Jacobian of $\mathbf{q}(\boldsymbol{\varphi})=\left(q^{1}(\boldsymbol{\varphi}), \ldots, q^{n}(\boldsymbol{\varphi})\right)^{T}$ evaluated at $\boldsymbol{\varphi}^{*}$. Moreover, let $V$ be the diagonal matrix with the $i$ th diagonal term equal to $v^{i}$. Given this we can define the following modified Katz-Bonacich centrality measure in $V, G^{T}$, and coefficients $\Psi$ and $\phi^{*}$ :

$$
\mathbf{b}^{\mathcal{M}}\left(\phi^{*}, V, G^{T}\right)=\left[I-\left(\phi^{*} G^{T}+\Psi D \mathbf{q}_{*}^{T} \cdot V\right)\right]^{-1} \cdot \mathbf{1} .
$$

This formula augments the standard Katz-Bonacich formula by incorporating information on the legislators' policy preferences and equilibrium pivot probabilities. It is easy to see that when $v^{i}=0$ for all $i$, it coincides with (4) with $\delta=\phi^{*}$ and $\hat{G}=G^{T}$.

Following the same steps as in the previous section, we can now characterize the equilibrium allocation solely in terms of the modified KatzBonacich centralities. We have the following proposition.

Proposition 2. With policy-motivated legislators, there is a unique equilibrium in which the interest groups choose the same vector of transfers $s_{* *}$. The vector $s_{* *}$ solves the problem

$$
\max _{\mathbf{s} \in S}\left\{\sum_{j} b_{j}^{\mathcal{M}}\left(\phi^{*}, V, G^{T}\right) \cdot \omega_{j}\left(s^{j}\right)\right\},
$$

where $b_{j}^{\mathcal{M}}\left(\phi^{*}, V, G^{T}\right)$ is the modified Katz-Bonacich centrality of $j$ in $V, G^{T}$ with coefficient $\phi^{*}=2 \Psi \phi$.

It should be stressed that $\mathbf{b}^{\mathcal{M}}\left(\phi^{*}, V, G^{T}\right)$ can be constructed exclusively using the exogenous fundamentals of the problem $q, \phi, V, G$, and $\Psi$, so it can itself be taken as a primitive of the model. Indeed $\mathbf{b}^{\mathcal{M}}\left(\phi^{*}, V, G^{T}\right)$ and the solution $\mathbf{S}_{* *}$ can be found following simple steps:

- Solve (14) to find $\varphi^{*}$ as function of the primitives (i.e., $q, \phi, V, G$, and $\Psi)$.

- Find $D \mathbf{q}_{*}$ exclusively as a function of $\varphi^{*}$.

- Compute $\mathbf{b}^{\mathcal{M}}\left(\phi^{*}, V, G^{T}\right)$ using (15) and solve (16) for $\mathbf{S}_{* *}$. 
A problem with proposition 2 is that it may be laborious to compute the vector of weights $\mathbf{b}^{\mathcal{M}}\left(\phi^{*}, V, G^{T}\right)$ for large networks since the construction of the pivot probabilities is quite complicated in the presence of many heterogeneous legislators with different voting probabilities. The weights $\mathbf{b}^{\mathcal{M}}\left(\phi^{*}, V, G^{T}\right)$, moreover, do not have an immediate interpretation in terms of the standard measures of network centrality because they do not depend only on the network topology $G$, but on preferences and the voting rule as well.

There are two cases in which we should expect the formulas in (15) to be simple. The first is when the legislators have weak preferences for the policy outcome, so $v_{i}$ is small in absolute value for all $i$. This is a simple implication of the fact that (15) is continuous in $v_{i}$, so the modified KatzBonacich centralities converge to the originals as $v_{i} \rightarrow 0$. Recalling that $\bar{v}=\max _{i}\left|v_{i}\right|$, we have the following corollary:

Corollary 1. The equilibrium allocation with policy-motivated legislators converges to the allocation with office-motivated legislators as $\bar{v} \rightarrow 0$.

In the second case, the number of legislators is large. Intuitively, we should expect pivot probabilities to be quite low and irrelevant in all cases except when $n$ is very small. In situations with a sufficiently large $n$ we should expect the social factors described by the simple Katz-Bonacich centralities to be dominant. To formalize this point, consider a sequence of networks $G_{n}$ with $n$ legislators of $m$ types $j=1, \ldots, m$ with associated sequences of equilibria with office-motivated legislators, $\mathbf{s}_{*}^{n}=\left(s_{*}^{n, 1}, \ldots, s_{*}^{n, n}\right)$, and policy-motivated legislators, $\mathbf{s}_{* *}^{n}=\left(s_{* *}^{n, 1}, \ldots, s_{* *}^{n, n}\right)$. In the case with policy-motivated legislators, the legislators' preferences are described by some vector $\mathbf{v}=\left(v_{1}, \ldots, v_{m}\right)$, where $v_{l}$ is the preference of a legislator of type $l=1, \ldots, m$. We have the following proposition:

Proposition 3. The equilibrium allocation with policy-motivated legislators converges to the allocation with office-motivated legislators as $n \rightarrow \infty$.

Proposition 3 make clear that when $n$ is large, the main determinant of the allocation of money is effectively the centrality of the legislator as measured by the standard Katz-Bonacich centralities $b_{j}\left(\phi^{*}, G^{T}\right)$. Therefore, when studying the US Congress (which has hundreds of legislators), it is essentially without loss of generality to use simple Katz-Bonacich centralities to predict how interest groups allocate resources.

\section{Evidence from the US Congress}

\section{A. Empirical Model}

To make the empirical predictions of the model precise, let us assume we observe data from $\bar{r}$ Congresses $(r=\{1, \ldots, \bar{r}\})$, each comprising $n$ con- 
gressmen, characterized by a network $G_{r}=\left[g_{i, j, r}\right]$. In equilibrium, each congressman $j$ receives an offer $s_{r, A}^{j}$ from $A$ and an offer $s_{r, B}^{j}$ from $B$, both equal to a common value $s_{r}^{j}$. Since the congressmen all vote for either $A$ or $B$, the model predicts that all congressmen receive a contribution $s_{r}^{j}$ with probability one.

Propositions 1-3 show that, in equilibrium, the contributions either solve (13) or are close to this solution. From the first-order necessary and sufficient condition of this problem we have $b_{j}\left(\phi^{*}, G_{r}^{T}\right) \cdot w_{j}^{\prime}\left(s_{r}^{j}\right)=\lambda$, where $b_{j}\left(\phi^{*}, G_{r}^{T}\right)$ is the Katz-Bonacich centrality of $j$ in Congress $r$ and $\lambda$ is the associated Lagrangian multiplier. We now assume that legislator $j$ 's utility takes the following form:

$$
\omega_{j}(s)=\xi_{0} \log \left(s+x_{j, r}^{T} \cdot \boldsymbol{\xi}_{1}+\epsilon_{j}\right),
$$

where $x_{j, r}$ is a column vector of characteristics of $j$ in Congress $r$ that may affect the legislators' preferences for contributions; $\xi_{0}$ and $\xi_{1}$ are preference parameters; and $\epsilon_{j}$ is an independently drawn random variable uncorrelated with $x_{j, r}$ with mean zero, describing heterogeneity in the legislators' preferences observed by the interest groups but not by the econometrician. For example, we expect that a legislator elected in a competitive district (as measured by the margin of victory in the previous election) will have a higher marginal valuation for contributions. It may also be, for example, that seniority, gender, or ideology affects a legislator's demand for contributions. ${ }^{23}$

Given (17), the interest groups' first-order necessary and sufficient condition for optimality can be written as $s_{r}^{j}=\left(\xi_{0} / \lambda\right) \cdot b_{j}\left(\phi^{*}, G_{r}^{T}\right)-x_{j, r}^{T} \xi_{1}-\epsilon_{j}$. Normalizing the signs of the coefficients, this relation can be rewritten in vector form:

$$
\mathbf{S}_{\mathbf{r}}=\alpha \cdot \mathbf{b}\left(\phi^{*}, G_{r}^{T}\right)+X_{r}^{T} \beta+\epsilon_{\mathbf{r}},
$$

where $\mathbf{s}_{\mathbf{r}}=\left(s_{1, r}, \ldots, s_{n, r}\right)^{T}, \epsilon_{\mathbf{r}}=\left(\epsilon_{1, r}, \ldots, \epsilon_{n, r}\right)^{T}, X_{r}=\left(x_{1, r}, \ldots, x_{n, r}\right)$, and the coefficients $\alpha, \phi^{*}$, and $\beta$ are the parameters to estimate. Condition (18) makes clear that monetary contributions to $j$ are predicted to be proportional to $j$ 's Katz-Bonacich.

For a sample with $\bar{r}$ networks, stack up the data by defining $\mathbf{s}=$ $\left(s_{1}^{T}, \ldots, s_{r}^{T}\right)^{T}, \quad \boldsymbol{\epsilon}=\left(\epsilon_{1}^{T}, \ldots, \epsilon_{r}^{T}\right)^{T}, \quad \mathbf{b}\left(\phi^{*}\right)=\left(\mathbf{b}\left(\phi^{*}, G_{1}^{T}\right)^{T}, \ldots, \mathbf{b}\left(\phi^{*}, G_{r}^{T}\right)^{T}\right)^{T}$, and $X=\left(X_{1}^{T}, \ldots, X_{\tilde{r}}^{T}\right)^{T}$. For the entire sample, the model is

$$
\mathbf{s}=\alpha \cdot \mathbf{b}\left(\phi^{*}\right)+X^{T} \boldsymbol{\beta}+\boldsymbol{\epsilon} .
$$

Model (19) cannot be estimated by simple ordinary least squares (OLS) in which $\mathbf{s}$ is the dependent variables and $\mathbf{b}\left(\phi^{*}\right)$ and $X$ are the indepen-

${ }^{23}$ We describe the control variables in greater detail in Sec. IV.B.2. 
dent variables because $\mathbf{b}\left(\phi^{*}\right)$ is a nonlinear function of a parameter to be estimated, $\phi^{*}$. We can, however, obtain estimates for $\alpha, \phi^{*}$, and $\beta$ from (19) by nonlinear least squares (NLLS).

This model allows us to obtain an estimate of the impact of a congressman's social ties on the allocation of PACs' campaign contributions. Two parameters appear especially important: $\phi^{*}$ and $\alpha$. Recall that $\phi^{*}=\Psi \phi$, where $\Psi$ is the density of the unobserved preference parameter $\varepsilon^{i}$ (see [1]) and $\phi$ is the parameter describing the network externality (again see [1]). Since $\Psi>0$, the social network matters in the allocation of political contributions if and only if $\phi^{*}>0$. The key hypothesis to be tested is therefore whether $\phi^{*}>0$. Parameter $\alpha$ is important because it gives us a direct estimate of the marginal impact of an increase in a legislator's Katz-Bonacich on his received contributions.

In Section IV.B, we describe the construction of the networks $G_{r}^{T}$, the control variables $x_{j, r}$, and the data on PAC contributions used for $\mathbf{s}$. In Section IV.C, we present the empirical results.

\section{B. Data Description}

1. The Alumni Network

In measuring social connections in Congress, there are two challenges. The first is the observability of the social network, since only in exceptional cases are the legislators' connections directly observable. ${ }^{24}$ The second is the problem of endogeneity, since there could be unobserved factors that simultaneously affect interest groups' allocations and the formation of social connections. The challenge is to find a measurement of social connections that is as much as possible extraneous to these factors or that at least allows us to control for them.

To address these issues, we exploit the idea that educational institutions provide a basis for social networks (see, among others, Cohen et al. [2008], Fracassi and Tate [2012], Cohen and Malloy [2014], and Do et al. [2016]). We therefore construct social networks using the congressmen's alumni connections: two congressmen are connected if they graduated from the same institution within a given time window. This approach gives us a network that is exogenous by construction to the political process and that, as we describe below, allows us to control for other possible confounding factors in a simple way.

To construct the network, we extract information on the educational institutions attended by the congressmen using the Biographical Directory

${ }^{24}$ Routt (1938) presents a quantitative analysis on the social interactions of the members of the floor of the Illinois Senate in 1937. Caldeira and Patterson (1987) analyze survey data from the 1965 Iowa Legislature. Arnold et al. (2000) present evidence from a survey of the Ohio Legislature in 1993. 
of the United States Congress, which is available online (http://bioguide .Congress.gov/biosearch/biosearch.asp). ${ }^{25}$ In our baseline version, we assume that a tie exists between two congressmen if they graduated from the same institution within 8 years of each other. More specifically, we set a link between two congressmen $g_{i, j}$ to be equal to the number of schools they both attended within 8 years of each other; we then row-normalize the social weights so that $\sum_{j} g_{i, j}=1$ for any $i_{.}{ }^{26}$ Since many legislators hold a primary and a secondary degree (typically a doctor of law or a master of business administration), this construction gives us a rich network of direct and indirect links.

By construction, the network $(N, g)$ described above can naturally be partitioned in multiple disconnected clusters of alumni (the network components, $\left.\left(N_{\theta}, g_{\theta}\right)_{\theta=1}^{J}\right) .{ }^{27} \mathrm{~A}$ component may comprise alumni from only one university in overlapping cohorts, if none of them attended any other school contemporaneously to other legislators; or it may comprise multiple universities, when alumni with multiple degrees are linked to alumni of different institutions. For example, figure 2 shows the largest components of the first (109th) and last (113th) Congresses in our sample. ${ }^{28}$ The figure shows that the components are the result of many overlapping peer groups (the shaded and labeled "clouds" around the nodes), where we define peer groups as groups of legislators who attended the same institution within 8 years of each other. The intersections between peer groups are induced by alumni with multiple degrees. The link between Harvard and West Point in the left panel of figure 2, for example, is established by Rep. Mike Pompeo (R) from Kansas's Fourth District (2011-17), who attended the US Military Academy at West Point and completed a JD at Harvard. In general, the number of components per Congress ranges from 34 in the 109th Congress to 42 in the 112th Congress, and they range in size from a minimum of two for the smallest peer groups (comprising only two alumni and one university) to 29 legislators for the maximal component in the 111th Congress.

Table A2 in the appendix presents the rankings of the top 30 legislators by centralities in the alumni network of the 109th Congress. From these rankings one can see that there are many legislators for whom the centrality

${ }^{25}$ We use high schools and academic institutions attended for both undergraduate and graduate degrees. In dealing with multiple campuses, we match each satellite campus as a separate university (e.g., University of California at Los Angeles, San Diego, and Berkeley are treated as separate universities). We match specialized schools (e.g., law schools) to the larger university.

${ }^{26}$ In Sec. V.G, we discuss alternative network constructions that use the alumni information in different ways and incorporate additional information.

27 A network matrix $G$ defines a network $(N, g)$ with $|N|$ legislators and links $g=\left(g_{i, j}\right)_{i, j \in N}$. The components $\left(N_{\theta}, g_{\theta}\right)_{\theta=1}^{J}$ of $(N, g)$ are the distinct maximal connected subgraphs of $(N, g)$.

${ }^{28}$ The layout of the graph has been produced using the force-directed graph-drawing algorithm by Kamada and Kawai (1989). 


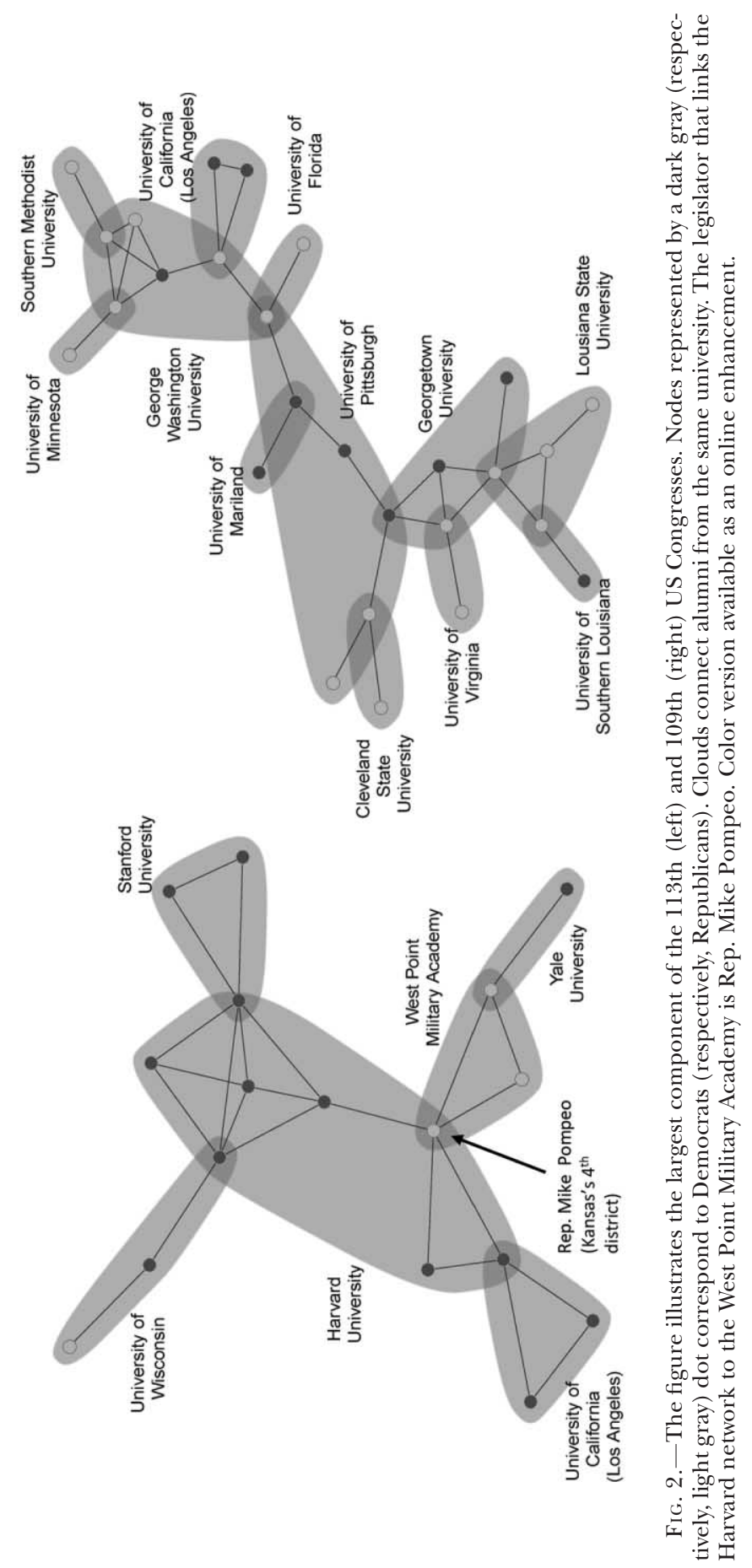


measures are quite correlated: Representatives Ben Cardin (D), Chet Edwards (D), and Jeff Fortenberry (R) are all examples of notable legislators whose centralities are generally high (and who have all received above the mean contributions) ${ }^{29}$ (Mike Pompeo, cited above, is not among them because he was elected in the 112th Congress: unsurprisingly, given the position in fig. 2 , he has also been ranked at the very top for most centralities since then.)

It is, however, not difficult to find examples of prominent legislators for whom the different measures give quite different results. Rep. Mike Oxley (R), for example, who served as chairman of the Committee on Financial Services and was House sponsor of the eponymous Sarbanes-Oxley Act of 2002, was tenth in terms of Katz-Bonacich centrality in our alumni network: however, he was not even represented in the top 30 list in terms of degree, betweenness, closeness, and eigenvector. Similarly, Rep. Debbie Wassermann Schultz (D), who later served as chairperson of the Democratic National Committee from 2011 to 2016, was the sixth-highest in terms of Katz-Bonacich centrality in the alumni network of the 109th Congress; but, again, she was not even represented in the top 30 list in terms of degree, betweenness, closeness, and eigenvector centralities. On the opposite spectrum, Rep. Donna Christian-Christensen (D), member of the US House of Representatives for the Virgin Islands' at-large district, was in the top 10 in terms of degree, betweenness, and closeness centralities, but she was not even represented in the top 30 list in terms of KatzBonacich centrality. ${ }^{30}$

Before using the network described above, we need to address two preliminary questions regarding our approach. The first question is whether the alumni network is still relevant many years after the congressmen attended school. The second question relates to the possible presence of other confounding factors associated with school quality that may affect the parameter estimates in (19).

Consider first the issue of relevance of the alumni network. To address it, we examine two distinct sources of information on legislative activity: data on cosponsorships and data on voting behavior. ${ }^{31}$ In table 1 , we estimate a dyadic regression model in which links between legislators $i$ and $j$ in the alumni network, $g_{i, j}^{A}$, and differences in terms of the legislators'

\footnotetext{
${ }^{29}$ Ben Cardin (D) served in many House committees including Ways and Means and was subsequently elected to the US Senate in 2006; Chet Edwards (D) was short-listed in 2008 as Barack Obama's vice president; Jeff Fortenberry (R) served in the Committee on Foreign Affairs and was listed in 2010 by the magazine Foreign Policy among the "foreignpolicy power brokers."

${ }^{30}$ Similar examples can be easily found for the other Congresses in our sample.

${ }^{31}$ We look at data on cosponsorships because they have been extensively used to study social networks in Congress starting from Fowler (2006). The link between peer connections and voting behavior in legislatures has instead been recently studied by Cohen and Malloy (2014) for the US Senate and by Harmon et al. (2018) for the European Parliament.
} 
TABLE 1

Predictive Power of Alumni Network for Cosponsorships and Voting Behavior

\begin{tabular}{|c|c|c|c|c|}
\hline & \multicolumn{4}{|c|}{ Dependent Variable } \\
\hline & \multicolumn{2}{|c|}{$\begin{array}{l}\text { A. Same Cosponsorship } \\
\text { Activity }\end{array}$} & \multicolumn{2}{|c|}{$\begin{array}{l}\text { B. Same Voting } \\
\text { Behavior }\end{array}$} \\
\hline & (1) & (2) & (3) & $(4)$ \\
\hline Link in alumni network $(1=$ yes $)$ & $\begin{array}{l}.1441 * * * \\
(.0122)\end{array}$ & $\begin{array}{l}.0399 * * * \\
(.0117)\end{array}$ & $\begin{array}{l}.0113 * * \\
(.005)\end{array}$ & $\begin{array}{l}.0118 * * \\
(.0051)\end{array}$ \\
\hline Same party $(1=$ yes $)$ & $\begin{array}{l}.2974 * * * \\
(.0027)\end{array}$ & $\begin{array}{l}.2914^{* * * *} \\
(.0027)\end{array}$ & $\begin{array}{l}.4322 * * * \\
(.0011)\end{array}$ & $\begin{array}{l}.4316^{* * * *} \\
(.0011)\end{array}$ \\
\hline Same gender $(1=$ yes $)$ & & $\begin{array}{l}.0015 \\
(.0029)\end{array}$ & & $\begin{array}{l}.0238 * * * \\
(.0013)\end{array}$ \\
\hline Same state $(1=$ yes $)$ & & $\begin{array}{l}.3266^{* * * *} \\
(.0054)\end{array}$ & & $\begin{array}{l}.0006 \\
(.0026)\end{array}$ \\
\hline Congress fixed effects & Yes & Yes & Yes & Yes \\
\hline$R^{2}$ & .1016 & .1267 & .7872 & .7891 \\
\hline Observations & 116,846 & 116,846 & 114,148 & 114,148 \\
\hline
\end{tabular}

NoTE.-OLS estimated coefficients are reported. An intercept is included. Standard errors (in parentheses) are clustered by dyad.

* Significant at the 10 percent level.

** Significant at the 5 percent level.

*** Significant at the 1 percent level.

characteristics are used as explanatory variables for cosponsorship activities in Congress. ${ }^{32}$ Cosponsorship activity is measured by directional links $g_{i, j}^{L}$ equal to one if $j$ has cosponsored at least one bill proposed by $i$ and zero otherwise. ${ }^{33}$ We thus run the following OLS regression:

$$
g_{i, j}^{L}=\gamma_{0}+\gamma_{1} g_{i, j}^{A}+\sum_{l} \gamma_{l}\left|x_{i}^{l}-x_{j}^{l}\right|+e_{i, j}
$$

where $e_{i, j}$ denotes an error term. Panel A of table 1 shows that two politicians who attended the same school at the same time are more likely to cosponsor a piece of legislation than two politicians who did not, holding constant similarities in observed characteristics.

We next look at the relationship between the alumni network and legislative voting. ${ }^{34}$ In panel B of table 1 we show the results for the estima-

${ }^{32}$ For each Congress, we control for legislators' similarities in terms of gender, party, and state (i.e., a dummy variable equal to one if they represent districts in the same state and zero otherwise). We also include school and Congress fixed effects.

${ }^{33}$ To construct the cosponsorship networks, we collect all pieces of legislation proposed in the US House from the 109th to the 113th Congresses from the Library of Congress data information system, THOMAS (http://thomas.loc.gov).

${ }^{34}$ If we assume that $G$ has all positive elements (as we do in our baseline network), then legislators $i$ and $j$ are more likely to vote together if they are linked in the network. This prediction, however, may fail to be true if $G$ has negative components. 
tion of model (20) in which the links $g_{i, j}^{L}$ are now the fraction of roll calls in which $i$ and $j$ cast the same vote. The set of control variables is unchanged. The estimation results show that two politicians who attended the same school at the same time are more likely to cast similar votes on a given proposal than those who did not. ${ }^{35}$

Consider now the second issue regarding potential confounding effects. Although the alumni network, by construction, is extraneous to the political process, it may be that some educational institutions attract students with similar characteristics or that the type of education provided by some institutions is pivotal in forming successful politicians or lobbyists. To control for these school effects, in all our regressions we include dummies for all the educational institutions (high schools, undergraduate, postgraduate) with at least five alumni in Congress (we report the top 50 educational institutions in terms of number of alumni in our sample in table A3 in the online appendix). Many universities (Harvard, Cornell, Duke, Stanford, Yale, and UCLA, among many others) serve as hubs to multiple peer groups in our sample. ${ }^{36}$ By including school dummies, we exploit variations in network centrality and contributions across alumni of the same school who belong to different cohorts.

\section{Control Variables}

The vector of variables $x_{i, r}$ (and the associated matrix $X$ ) measures the susceptibility of a congressman to PAC contributions. The classic variables used to explain campaign contributions to legislators in the literature are the degree of electoral competition, measures of members' relative "power" inside the House, and indicators of a congressman's ideology, political party, gender, and seniority in his current committee. ${ }^{37}$

Information on politicians' characteristics including gender and party of affiliation is provided by GovTrack. Charles Stewart and Jonathon Woon's website is used to obtain information on committee appointments, se-

\footnotetext{
${ }^{35}$ Data on all votes in the 109th-113th Congresses can be accessed from http:// voteview.com. More than 7,500 proposals were proposed. For each pair of congressmen in our network, we considered the proposals for which both were present and voted. Delegates are excluded since they do not vote from the House floor.

${ }^{36}$ As defined before, a peer group is defined as a group of congressmen who attended the same institution in overlapping periods of time.

${ }^{37}$ For electoral competitiveness, the idea is that a close race increases an incumbent's demand for PAC contributions, producing an exogenous shift in contributions via an increase in the propensity to "sell" services, including roll call votes. For the "power" of a member, the argument is that groups give more to powerful members because their support is especially valuable. The inclusion of the politicians' ideologies captures the fact that congressmen with more extreme ideologies may be more or less susceptible to persuasion. The inclusion of these variables can also help control for other factors affecting the extensive margin (who is elected to Congress) that may be relevant for interest groups.
} 
niority, and chairmanship. ${ }^{38}$ For each congressman, electoral competition is measured by the margin of victory. ${ }^{39}$ Each candidate's margin of victory is derived from the Federal Election Commission's Federal Elections publications. These publications provide statistics on candidates' vote shares. Since the publications often omit special election results, we supplement the FEC reports with information from individual state agencies. The ideologies of the congressmen are measured using the first dimension of the DW-Nominate score (McCarty, Poole, and Rosenthal 1997).$^{40}$ The "power" of the congressman is measured by three variables. First, we have a dummy variable indicating whether the member is a committee chair. ${ }^{41}$ Second, we have a dummy variable indicating that the member belongs to the party that has the majority in the House. Finally, we include a dummy variable indicating whether the politician is on one of the powerful committees (Ways and Means, Energy and Commerce, Appropriations, Rules, or Financial Services), in which an individual is likely to receive greater PAC contributions (see Grier and Munger 1991, 1993; Romer and Snyder 1994).

To control for electoral cycle fixed effects, we include in our analysis four election cycle dummies (associated with each Congress). These are intended to control for changes in the number of PACs over time and changes in nominal and real PAC budgets, as well as for Congressspecific factors affecting PAC contributions.

Finally, we add a dummy variable taking a value of one if the congressman did not graduate from the same institution within 8 years with any other congressman to control for unobserved differences between connected and unconnected congressmen. Table A1 contains a detailed description of our data, as well as summary statistics for our sample.

\section{Campaign Contributions Data}

Campaign contributions data from the FEC files are collected and aggregated by the Center for Responsive Politics (CRP). The CRP provides details on the date, type, industry with which the PAC is associated, and recipient of each contribution. We consider the total amount of contributions from PACs and reduce the effect of possible outliers by trimming the dis-

\footnotetext{
${ }^{38}$ See http://web.mit.edu/17.251/www/data_page.html\#2. This website does not contain information for the 113th Congress. We extract the House of Representatives committee roster for the 113th Congress from the website http://media.cq.com/pub/committees/index.php.

${ }^{39}$ Margin of victory as a measure of electoral competition is used by Poole, Romer, and Rosenthal (1987), Grier and Munger (1991), and Romer and Snyder (1994), among others.

${ }^{40}$ To isolate this index for one Congress at a time, we used the modified DW-Nominate coordinates developed by Nokken and Poole (2004). Data are available at http://voteview .com.

${ }^{41}$ A dummy variable for committee leadership is used in Romer and Snyder (1994).
} 
tribution at the 1st and 99th percentiles. ${ }^{42}$ In our data, the money spent by PACs for a given candidate ranges from $\$ 10,750$ to $\$ 10,789,346$, whereas total spending ranges from $\$ 334$ million for the 109 th Congress to $\$ 419$ million for the 113th Congress.

\section{Empirical Findings}

Table 2 presents the estimates of our model (eq. [19]), with an increasing set of controls. The two key parameters to estimate are $\phi^{*}$, which measures the network externality in the model, and $\alpha$, which measures the impact of a marginal increase in the Katz-Bonacich centrality of a legislator on the associated interest groups' contributions. Both parameters are predicted to be positive. As can be seen from columns 1-4 of table 2, the estimates reveal a positive and statistically significant estimate of both $\phi^{*}$ and $\alpha$ for all sets of controls. We estimate that a one standard deviation increase in a legislator's Katz-Bonacich centrality induces an increase of about $\$ 16,000$ in interest group contributions. To put this in context, it roughly corresponds to the increase that a legislator achieves by being a member of the majority party.

It is interesting to note that we find the effects of the margin of victory, chair, and majority party all to be significant and with the expected sign. A positive effect of chair confirms the fact that congressmen in positions of leadership receive more attention from interest groups. Members of the majority party receive more contributions than members of the opposition party (in our sample, Republicans had the majority in all Congresses we consider except for the first two). The estimated effect of the margin of victory coefficient suggests that congressmen who face tight elections have higher needs for campaign finance, are more susceptible to interest groups' influence, and therefore receive more money. Being female is associated with receiving less contributions. The negative effect of seniority is consistent with the results in Grier and Munger (1986). A positive and statistically significant effect of DW ideology indicates that politicians with more extreme ideologies receive more money. The estimated effect of sitting on a relevant committee is not statistically different from zero.

The findings discussed above should be contrasted with two benchmarks: the OLS estimates ignoring the network effects and estimates using other standard measures of centrality that do not have a theoretical foundation. With respect to the first benchmark, column 5 of table 2 reports the OLS estimates of the traditional model in which campaign contributions are explained using legislators' characteristics and school and

${ }^{42}$ These data have been extensively used in the literature on economics and politics, following Poole and Rosenthal (1997). 
TABLE 2

Main Estimation Results

\begin{tabular}{|c|c|c|c|c|c|}
\hline & \multicolumn{5}{|c|}{ DePendent VARIABle: PAC Contributions (\$Millions) } \\
\hline & $(1)$ & $(2)$ & (3) & (4) & (5) \\
\hline \multirow[t]{2}{*}{ Network effects $(\phi)$} & $.0268 * *$ & $.0265^{* *}$ & $.0352 * *$ & $.0352 * * *$ & \\
\hline & $(.0098)$ & $(.0131)$ & $(.0107)$ & $(.0106)$ & \\
\hline \multirow[t]{2}{*}{ Katz-Bonacich $(\alpha)$} & $1.2536 * * *$ & $1.1735 * * *$ & $.8775 * * *$ & $.8794 * * *$ & \\
\hline & $(.1041)$ & $(.1121)$ & $(.1241)$ & $(.1258)$ & \\
\hline \multirow[t]{2}{*}{ Unconnected } & $-.1294 * *$ & $-.1243^{*}$ & $-.1056^{*}$ & $-.1054 *$ & $-.1157 *$ \\
\hline & $(.0633)$ & $(.0706)$ & $(.0632)$ & $(.0631)$ & $(.0632)$ \\
\hline \multirow[t]{2}{*}{ Party (1 = Democrat) } & $-.1365^{* *}$ & $-.1131^{* *}$ & .0213 & .0214 & .0205 \\
\hline & $(.0432)$ & $(.0382)$ & $(.0493)$ & $(.0493)$ & $(.0491)$ \\
\hline \multirow[t]{2}{*}{ Gender ( 1 = female $)$} & $-.6145^{* * *}$ & $-.5969 * * *$ & $-.4946^{* * *}$ & $-.4956 * * *$ & $-.4685^{* * *}$ \\
\hline & $(.0342)$ & $(.0302)$ & $(.0422)$ & $(.0439)$ & $(.0418)$ \\
\hline \multirow[t]{2}{*}{ Chair ( 1 = yes $)$} & $.3986 * * *$ & $.4098 * * *$ & $.349 * * *$ & $.3494 * * *$ & $.3353 * * *$ \\
\hline & $(.093)$ & $(.0939)$ & $(.0943)$ & $(.0944)$ & $(.0906)$ \\
\hline \multirow[t]{2}{*}{ Seniority } & $-.0185^{* * * *}$ & $-.0166^{* * *}$ & $-.0139 * * *$ & $-.0141 * * *$ & $-.0058 * * *$ \\
\hline & $(.0027)$ & $(.0026)$ & $(.0026)$ & $(.0029)$ & $(.0017)$ \\
\hline \multicolumn{6}{|l|}{ Margin of victory } \\
\hline \multirow{2}{*}{$(1=$ less than $5 \%)$} & & $.0942 * * *$ & $.9691 * * *$ & $.9683 * * *$ & $1.0027 * * *$ \\
\hline & & $(.0969)$ & $(.1559)$ & $(.1562)$ & $(.1601)$ \\
\hline \multirow[t]{2}{*}{ DW ideology } & & & $.3042 * * *$ & $.305^{* * *}$ & $.3739 * * *$ \\
\hline & & & $(.0859)$ & $(.0855)$ & $(.085)$ \\
\hline \multirow[t]{2}{*}{ Majority party (1 = yes) } & & & $.1135^{* * *}$ & $.1137 * * *$ & $.0488^{*}$ \\
\hline & & & $(.0278)$ & $(.028)$ & $(.0261)$ \\
\hline \multirow[t]{2}{*}{ Relevant committee $(1=$ yes $)$} & & & & -.0038 & $.0416 *$ \\
\hline & & & & $(.029)$ & $(.0252)$ \\
\hline School fixed effects & Yes & Yes & Yes & Yes & Yes \\
\hline Congress fixed effects & Yes & Yes & Yes & Yes & Yes \\
\hline Partial $F$-test $(\phi=0)$ & & & & & $5.9204 * * *$ \\
\hline$p$-value & & & & & {$[.000]$} \\
\hline Observations & 2,125 & 2,125 & 2,125 & 2,125 & 2,125 \\
\hline
\end{tabular}

Note.-NLLS estimated coefficients are reported in cols. 1-4. OLS estimated coefficients are reported in col. 5. An intercept is included. Robust standard errors are in parentheses. A precise definition of control variables can be found in table A1.

* Significant at the 10 percent level.

** Significant at the 5 percent level.

*** Significant at the 1 percent level.

Congress fixed effects, ignoring the fact that congressmen are connected. The important observation is that the inclusion of network effects significantly improves the fit of the model. We formally test the fit increase of our model with network externalities compared to the traditional linear regression with $\phi^{*}=0$ using a partial $F$-test. ${ }^{43}$ The $F$-test rejects the hypoth-

${ }^{43}$ Let $\mathrm{RRS}_{1}$ define the residual sum of squares of the unrestricted model (col. 4) and $p_{1}$ the number of parameters. Let $\mathrm{RRS}_{2}$ be the residual sum of squares of the restricted model (col. 5) and $p_{2}$ the number of parameters. The partial $F$-test statistic, $F=$ $\left[\left(\mathrm{RRS}_{1}-\mathrm{RRS}_{2}\right) / p_{1}-p_{2}\right] /\left(\mathrm{RRS}_{1}\right) / n-p_{1}$, will have an $F$ distribution with $\left(p_{1}-p_{2}, n-p_{1}\right)$ degrees of freedom. 
esis that the model with $\phi^{*} \neq 0$ does not provide a significantly better fit than the model with $\phi^{*}=0(p<.001)$.

With respect to the second benchmark, we compare the predictions of our model with the predictions obtained using other standard measures of network centrality (which are not supported by a theoretical analysis). Table 3 presents OLS estimates of the relationship between PAC electoral

TABLE 3

Explicative Power of Traditional Network Measures

\begin{tabular}{|c|c|c|c|c|c|}
\hline & \multicolumn{5}{|c|}{ Dependent Variable: PAC Contributions (\$Millions) } \\
\hline & (1) & (2) & $(3)$ & $(4)$ & (5) \\
\hline \multicolumn{6}{|l|}{ Centrality measures: } \\
\hline Degree & $\begin{aligned}-.0039 \\
(.0087)\end{aligned}$ & & & & $\begin{array}{r}-.0457 \\
(.0385)\end{array}$ \\
\hline Betweenness & & $\begin{array}{l}-.0098 * * \\
(.0048)\end{array}$ & & & $\begin{array}{l}.0510^{*} \\
(.0298)\end{array}$ \\
\hline Closeness & & & $\begin{array}{l}.8827 * * * \\
(.3473)\end{array}$ & & $\begin{array}{c}.8716 \\
(1.7437)\end{array}$ \\
\hline Eigenvector & & & & $\begin{array}{l}-.4820 \\
(.3355)\end{array}$ & $\begin{array}{l}.0924 \\
(.5587)\end{array}$ \\
\hline$\phi$ & & & & & $\begin{array}{l}.0877 * * \\
(.0352)\end{array}$ \\
\hline Katz-Bonacich $(\alpha)$ & & & & & $\begin{array}{l}.8813^{* * * *} \\
(.1311)\end{array}$ \\
\hline Unconnected & $\begin{array}{c}-.1208^{*} \\
(.0647)\end{array}$ & $\begin{array}{c}-.1189 * \\
(.0632)\end{array}$ & $\begin{array}{r}-.0968 \\
(.0629)\end{array}$ & $\begin{array}{r}-.1248^{*} \\
(.0642)\end{array}$ & $\begin{array}{l}-.1018 \\
(.0705)\end{array}$ \\
\hline Party (1 = Democrat) & $\begin{array}{c}.0199 \\
(.0492)\end{array}$ & $\begin{array}{l}.0198 \\
(.0491)\end{array}$ & $\begin{array}{l}.0206 \\
(.0491)\end{array}$ & $\begin{array}{l}.0222 \\
(.0491)\end{array}$ & $\begin{array}{l}.0203 \\
(.0495)\end{array}$ \\
\hline Gender $(1$ = female $)$ & $\begin{array}{l}-.4694 * * * \\
(.0421)\end{array}$ & $\begin{array}{l}-.4706 * * * \\
(.0419)\end{array}$ & $\begin{array}{l}-.472 * * * \\
(.042)\end{array}$ & $\begin{array}{l}-.4686 * * * \\
(.0418)\end{array}$ & $\begin{array}{l}-.4957 * * * \\
(.044)\end{array}$ \\
\hline Chair $(1=$ yes $)$ & $\begin{array}{l}.3373^{* * *} \\
(.091)\end{array}$ & $\begin{array}{l}.3392 * * * \\
(.0908)\end{array}$ & $\begin{array}{l}.3422 * * * \\
(.0909)\end{array}$ & $\begin{array}{l}.3381 * * * \\
(.0907)\end{array}$ & $\begin{array}{l}.3493 * * * \\
(.0943)\end{array}$ \\
\hline Seniority & $\begin{array}{l}-.0061 * * \\
(.0021)\end{array}$ & $\begin{array}{l}-.0065^{* * * *} \\
(.0017)\end{array}$ & $\begin{array}{l}-.0068^{* * * *} \\
(.0018)\end{array}$ & $\begin{array}{l}-.0058 * * * \\
(.0017)\end{array}$ & $\begin{array}{l}-.0145^{* * *} \\
(.0029)\end{array}$ \\
\hline DW ideology & $\begin{array}{l}.3712 * * * \\
(.0856)\end{array}$ & $\begin{array}{l}.3695 * * * \\
(.0849)\end{array}$ & $\begin{array}{l}.3707 * * * \\
(.085)\end{array}$ & $\begin{array}{l}.3739 * * * \\
(.085)\end{array}$ & $\begin{array}{l}.2971 * * * \\
(.0851)\end{array}$ \\
\hline Majority party $(1=$ yes $)$ & $\begin{array}{l}.0489 * \\
(.0261)\end{array}$ & $\begin{array}{l}.0497^{*} \\
(.0265)\end{array}$ & $\begin{array}{l}.0497^{*} \\
(.0265)\end{array}$ & $\begin{array}{l}.0487 * \\
(.0261)\end{array}$ & $\begin{array}{l}.1098^{* * * *} \\
(.0282)\end{array}$ \\
\hline $\begin{array}{l}\text { Margin of victory } \\
\qquad(1=\text { less than } 5 \%)\end{array}$ & $\begin{array}{l}1.002 * * * \\
(.1601)\end{array}$ & $\begin{array}{l}1.0004 * * * \\
(.1598)\end{array}$ & $\begin{array}{l}.9978 * * * \\
(.1596)\end{array}$ & $\begin{array}{l}1.0032 * * * \\
(.1599)\end{array}$ & $\begin{array}{l}.9722 * * * \\
(.1557)\end{array}$ \\
\hline $\begin{array}{l}\text { Relevant committee } \\
\qquad(1=\text { yes })\end{array}$ & $\begin{array}{l}.0413 \\
(.0254)\end{array}$ & $\begin{array}{l}.0391 \\
(.0264)\end{array}$ & $\begin{array}{c}.0352 \\
(.0267)\end{array}$ & $\begin{array}{l}.0421^{*} \\
(.0252)\end{array}$ & $\begin{array}{c}-.0069 \\
(.0287)\end{array}$ \\
\hline School fi: & Yes & Yes & Yes & Yes & Yes \\
\hline xed effects & Yes & Yes & Yes & Yes & Yes \\
\hline Observations & 2,125 & 2,125 & 2,125 & 2,125 & 2,125 \\
\hline
\end{tabular}

NotE.-NLLS estimates are reported in col. 5. OLS estimates are reported in cols. 1-4. An intercept is included. Robust standard errors are reported in parentheses. A precise definition of control variables can be found in table A1.

* Significant at the 10 percent level.

** Significant at the 5 percent level.

*** Significant at the 1 percent level. 
contributions and degree, betweenness, closeness, and eigenvalue centralities ${ }^{44}$ As can be seen from columns 1 and 4 , the effects of degree and eigenvalue centralities are not significantly different from zero. Column 2 shows that the effect of betweenness is statistically significant but insignificant in magnitude and negative, and column 3 shows that closeness centrality has a positive and statistically significant effect. The magnitude of its impact in terms of money is, however, about one-fourth of the estimated impact of Katz-Bonacich centrality in table 2 (col. 4). All the control variables have the expected signs, the same as in the estimates of table 2. The important observation is that when those centrality measures are included in a regression model together with Katz-Bonacich centrality (col. 5), the effect of Katz-Bonacich is the only one to remain strong and statistically significant. Betweenness shows an effect at the edge of the statistical significance, but that is less than half the impact of the Katz-Bonacich in terms of point estimates, whereas the effects of all the other centrality measures cannot be distinguished from zero.

\section{Discussions and Extensions}

\section{A. Heterogeneous Social Spillovers}

In (1), we assumed that the parameter directly associated with network externalities, that is, $\phi$, is constant across legislators. Depending on personal characteristics, however, legislators may be more or less susceptible to social spillovers. Spillovers, for example, may depend on whether legislators belong to the majority or not or on their gender; spillovers, moreover, may be different for legislators in very dense network components. When we allow for heterogeneous spillovers we have

$$
U^{i}(p)=\omega\left(s^{i}(p)\right)+\phi_{i} \sum_{j} g_{i, j} \chi_{j}(p)+\varepsilon_{p}^{i},
$$

where $\phi_{i}$ now depends on $i$ 's characteristics. The model with these preferences can be analyzed similarly to the previous models. Let us assume for simplicity that legislators are office motivated (the analysis can be easily extended to policy-motivated legislators). Using (21) and differentiating the voting probabilities in a way similar to $(7)$, we obtain $D_{i}[\varphi]=$ $\Psi[I-\Lambda \cdot G]^{-1} D_{i}[\omega]$, where $\Lambda$ is a diagonal matrix with the $i$ th diagonal el-

\footnotetext{
${ }^{44}$ Degree centrality counts the total number of direct connections. Closeness centrality measures the length of the average shortest path passing between a node and each other node. Betweenness is equal to the number of shortest paths from all nodes to each other that pass through that node. Eigenvalue centrality of node $i$ is the $i$ th component of the eigenvector associated to the highest eigenvalue of $G$. See Jackson (2008) for an introduction and detailed description of these measures.
} 
ement equal to $2 \Psi \phi_{i}{ }^{45}$ Substituting in the first-order necessary and sufficient condition as in (11), we obtain

$$
D_{i}[\boldsymbol{\varphi}]^{T} \cdot \mathbf{1}=\lambda_{*} \Rightarrow \Psi \cdot D_{i}[\boldsymbol{\omega}]^{T} \cdot\left(I-G^{T} \cdot \Lambda\right)^{-1} \cdot \mathbf{1}=\lambda_{*} .
$$

Let us define $\mathbf{b}^{\mathcal{H}}\left(G^{T}, \Lambda\right)=\left(b_{i}^{\mathcal{H}}\left(G^{T}, \Lambda\right), \ldots, b_{i}^{\mathcal{H}}\left(G^{T}, \Lambda\right)\right)^{T}$ as

$$
\mathbf{b}^{\mathcal{H}}\left(G^{T}, \Lambda\right)=\left(I-G^{T} \cdot \Lambda\right)^{-1} \cdot \mathbf{1} .
$$

The vector $\mathbf{b}^{\mathcal{H}}\left(G^{T}, \Lambda\right)$ is a straightforward generalization of the standard Katz-Bonacich centrality measure, in which the decay factors can be heterogeneous and are given by the diagonal elements of $\Lambda$. Condition (22) can now be written as $b_{i}^{\mathcal{H}}\left(G^{T}, \Lambda\right) \cdot \omega^{\prime}\left(s_{*}^{i}\right)=\lambda_{*}$ for $i=1, \ldots, n$. When we allow for heterogeneous spillovers, the model predicts that the interest moneys should be allocated in a way that is proportional to the heterogeneous centrality measure $\mathbf{b}^{\mathcal{H}}\left(G^{T}, \Lambda\right)$.

Our new equilibrium condition can be easily brought to the data. To this goal, let us assume $\phi_{i}=\left(\theta_{0}+z_{i}^{T} \theta_{1}\right)$, where $z_{i}=\left(z_{i}^{1}, \ldots, z_{i}^{q}\right)^{T}$ is a $q$-dimensional column vector of $i$ s characteristics relevant for $\phi_{i}$, and $\theta=$ $\left(\theta_{0}, \theta_{1}^{1}, \ldots, \theta_{1}^{t}\right)$ are underlying parameters to estimate. Using (17), we can write the equilibrium condition as

$$
\mathbf{s}=\alpha \cdot \mathbf{b}^{\mathcal{H}}\left(G^{T}, \Lambda(\theta, Z)\right)+X^{T} \beta+\epsilon,
$$

where $\Lambda(\theta, Z)$ is a diagonal matrix with the $i$ th element equal to $2 \Psi\left(\theta_{0}+\right.$ $z_{i}^{T} \theta_{1}$ ). The parameters of (23) can now be estimated with an NLLS approach similar to the estimation of (19).

As a first look into the issue of heterogeneity for network spillovers, in column 1 of table 4 we present the estimation of (23) in which we allow $\phi_{i}$ to depend on $i$ 's gender and on whether $i$ belongs to the majority party by adding gender and majority party in the $Z$ variables. In column 2 of table 4 we investigate whether network effects are different for legislators who are in dense components by adding a dummy variable taking a value one if the politician belongs to a network component with density in the top quartile (the 75 th percentile in our sample is equal to 0.57 ). The estimation results show that, while the personal characteristics are significant in shaping spillover effects, the density of the associated network component does not seem to be relevant.

\section{B. Multiple Interest Groups}

In the preceding analysis, we maintained the assumption of two interest groups, one for $A$ and one for $B$. It is natural to extend the results to the

\footnotetext{
${ }^{45}$ Note that when $\phi_{i}=\phi$ for all $i$, then the expression for $D_{i}[\varphi]$ presented above collapses
} to $(7)$. 
TABLE 4

Additional Results

\begin{tabular}{|c|c|c|c|c|}
\hline & \multicolumn{4}{|c|}{$\begin{array}{l}\text { DePendent Variable: PAC Contributions } \\
\text { (\$Millions) }\end{array}$} \\
\hline & (1) & (2) & (3) & (4) \\
\hline Network effects $(\phi)$ & $\begin{array}{l}.0004 * * \\
(.0001)\end{array}$ & $\begin{array}{l}.0293 * * * \\
(.0100)\end{array}$ & $\begin{array}{l}.4975^{* * * *} \\
(.0002)\end{array}$ & $\begin{array}{l}.4977 * * * \\
(.0004)\end{array}$ \\
\hline Katz-Bonacich $(\alpha)$ & $\begin{array}{l}.7826 * * * \\
(.0707)\end{array}$ & $\begin{array}{l}.9261 * * * \\
(.1279)\end{array}$ & $\begin{array}{l}.0025^{* * *} \\
(.0007)\end{array}$ & $\begin{array}{l}.6652 * * * \\
(.1908)\end{array}$ \\
\hline Network effects $\times$ majority party $(1=$ yes $)$ & $\begin{array}{l}.2318^{* * * *} \\
(.0730)\end{array}$ & & & \\
\hline Network effects $\times$ gender $(1=$ female $)$ & $\begin{array}{l}.1876^{* * * *} \\
(.0662)\end{array}$ & & & \\
\hline $\begin{array}{l}\text { Network effects } \times \text { network density } \\
\quad(1=\text { higher than the } 75 \text { th percentile })\end{array}$ & & $\begin{array}{r}-.0088 \\
(.1264)\end{array}$ & & \\
\hline $\begin{array}{l}\text { Network density }(1=\text { higher than the } \\
75 \text { th percentile })\end{array}$ & & $\begin{array}{c}-.1650 \\
(.1176)\end{array}$ & & \\
\hline Unconnected & $\begin{array}{r}-.0101 \\
(.6701)\end{array}$ & $\begin{array}{l}-.1447 * * \\
(.0651)\end{array}$ & $\begin{array}{l}.1550 * * * \\
(.0520)\end{array}$ & $\begin{array}{l}.1537 * * * \\
(.0521)\end{array}$ \\
\hline Party (1 = Democrat) & $\begin{array}{l}.3564 * * * \\
(.0396)\end{array}$ & $\begin{array}{l}.0167 \\
(.0497)\end{array}$ & $\begin{array}{l}.1728 * * * \\
(.0447)\end{array}$ & $\begin{array}{l}.1760 * * * \\
(.0447)\end{array}$ \\
\hline Gender $(1=$ female $)$ & $\begin{array}{l}-.3064^{* * * *} \\
(.0343)\end{array}$ & $\begin{array}{l}-.4958 * * * \\
(.0438)\end{array}$ & $\begin{array}{l}-.4130 * * * \\
(.0416)\end{array}$ & $\begin{array}{l}-.4135^{* * * *} \\
(.0416)\end{array}$ \\
\hline Chair $(1$ = yes $)$ & $\begin{array}{l}.3559 * * * \\
(.0984)\end{array}$ & $\begin{array}{l}.3647 * * * \\
(.0945)\end{array}$ & $\begin{array}{l}.3508 * * * \\
(.0909)\end{array}$ & $\begin{array}{l}.3513^{* * * *} \\
(.0909)\end{array}$ \\
\hline Seniority & $\begin{array}{r}-.0033 \\
(.0025)\end{array}$ & $\begin{array}{l}-.0155^{* * * *} \\
(.0029)\end{array}$ & $\begin{array}{c}-.0095^{* * * *} \\
(.0027)\end{array}$ & $\begin{array}{c}-.0097 * * * \\
(.0027)\end{array}$ \\
\hline DW ideology & $\begin{array}{l}.8374 * * * \\
(.0562)\end{array}$ & $\begin{array}{l}.2661 * * * \\
(.0855)\end{array}$ & $\begin{array}{l}.5701^{* * * *} \\
(.0726)\end{array}$ & $\begin{array}{l}.5666^{* * * *} \\
(.0725)\end{array}$ \\
\hline Majority party $(1$ = yes $)$ & $\begin{array}{l}.1469 * * * \\
(.0326)\end{array}$ & $\begin{array}{l}.1051^{* * * *} \\
(.0281)\end{array}$ & $\begin{array}{l}.1293^{* * * *} \\
(.0287)\end{array}$ & $\begin{array}{l}.1285^{* * * *} \\
(.0287)\end{array}$ \\
\hline Margin of victory $(1=$ less than $5 \%)$ & $\begin{array}{l}1.1438 * * * \\
(.1605)\end{array}$ & $\begin{array}{l}.9651^{* * * *} \\
(.1556)\end{array}$ & $\begin{array}{l}1.0350 * * * \\
(.1579)\end{array}$ & $\begin{array}{l}1.0250 * * * \\
(.1586)\end{array}$ \\
\hline Relevant committee $(1=$ yes $)$ & $\begin{array}{l}.1054 \\
(.02706)\end{array}$ & $\begin{array}{l}.0073 \\
(.02794)\end{array}$ & $\begin{array}{c}.0219 \\
(.0278)\end{array}$ & $\begin{array}{c}.0219 \\
(.0278)\end{array}$ \\
\hline School fixed effects & Yes & Yes & Yes & Yes \\
\hline Congress fixed effects & Yes & Yes & Yes & Yes \\
\hline Observations & 2,125 & 2,125 & 2,125 & 2,125 \\
\hline
\end{tabular}

NoTE.-NLLS estimated coefficients and robust standard errors (in parentheses) are reported. A precise definition of control variables can be found in table Al. Columns 1 and 2 include interaction terms with personal and network characteristics according to the theoretical eq. (23). In col. 3, the alumni network is not row-normalized. In col. 4, it is weighted by party affiliation. Weights take values of 1 if the linked congressmen have the same school and party, 0.5 if they have the same school and a different party, 0 if they have a different school and the same party, and -0.5 if they have a different school and a different party.

* Significant at the 10 percent level.

** Significant at the 5 percent level.

*** Significant at the 1 percent level. 
case in which we have $K$ interest groups for $A$ and $K$ for $B$, each endowed with a budget $W$. Let $s_{j, A}^{i}$ be the contribution promised by the $j$ th interest group for $A$ to the $i$ th legislator with $\mathbf{s}_{j, A}=\left(s_{j, A}^{1}, \ldots, s_{j, A}^{n}\right)$ and $\mathbf{s}_{A}=$ $\left(\mathbf{s}_{1, A}, \ldots, \mathbf{s}_{K, A}\right)$. The problem faced by an interest group $j$ of type $A$ is similar to (9), with the only difference being that now both $\mathbf{s}_{-j, A}$, the choice of all other $K-1$ interest groups supporting $A$, and $\mathbf{s}_{B}$, the choice of all $K$ interest groups supporting $B$, are taken as given.

Following the same steps as above, we can show that, if legislators are office motivated or if they are policy motivated and there is sufficient uncertainty on their preferences, there is a unique equilibrium in which all interest groups commit to the same transfer $s_{j, A}^{i}=s_{k, B}^{i}=s_{*}^{i}$ for any $j, k$, and $i$. This implies that the voting probabilities are derived exactly as in Section III.B. The analysis is unaffected by the size of $K$ because the marginal effect of a contribution on the voting probabilities is independent of the contributions of other interest groups. ${ }^{46}$ Assuming, as in Section IV.A, that the monetary utility is as in (17), we have that the total contribution received for voting $A$ in Congress $r$ is just $K$ times the formula in (18). Since these values differ from the previous analysis only by a factor of proportionality, there is no qualitative change in the result and its implications for the empirical analysis.

\section{Asymmetric Interest Groups}

In the previous analysis we assume that the two interest groups are symmetric; that is, they have the same budgets and the same preferences. In this case we have $s_{A}=s_{B}$, so these expressions disappear from (5): this implies that the interest groups offset each other and, in equilibrium, they have no effect on voting probabilities (which are determined only by the legislators' preferences and the network). In our model, however, the analysis can be extended to the case of asymmetric interest groups with minimal complications. Consider first the case with office-motivated legislators and assume $A$ has a larger budget than $B: W_{A}>W_{B}$. Because (5) is linear in $s_{A}$ and $s_{B}$ when $v_{j}=0, j=A, B$, the first-order necessary and sufficient conditions (10) remain unchanged, except that now the Lagrangian multipliers are different and $\operatorname{so} s_{A}^{i}>s_{B}^{i}$. The qualitative prediction of the model, however, remains identical to the previous analysis: the contribution to legislator $i$ by interest group $j$ is proportional to $i$ s Katz-Bonacich centrality. The factor of proportionality now can be different between interest groups.

${ }^{46}$ This can be seen from (6) with office-motivated and (A1) with office- and policymotivated legislators. 
Consider the case with policy-motivated legislators. The first-order necessary and sufficient conditions of (16) are

$$
b_{j}^{\mathcal{M}}\left(\phi^{*}, V, G^{T}\right) \cdot \omega_{j}^{\prime}\left(s_{l}^{j}\right)=\lambda_{l} \quad \forall j \in N,
$$

and the voting probabilities are determined by the system of equations

$$
\left.\left(\begin{array}{c}
\varphi_{1}^{*} \\
\cdots \\
\varphi_{n}^{*}
\end{array}\right)=\left(\begin{array}{c}
\frac{1}{2}+\Psi\left(\omega\left(s_{A}^{1}\right)-\omega\left(s_{B}^{1}\right)+v^{1} q^{1}(\boldsymbol{\varphi})+\phi \sum_{j} g_{1, j}\left(2 \varphi_{j}^{*}-1\right)\right. \\
\cdots \\
\frac{1}{2}+\Psi\left(\omega\left(s_{A}^{n}\right)-\omega\left(s_{B}^{n}\right)+v^{n} q^{n}(\boldsymbol{\varphi})+\phi \sum_{j} g_{n, j}\left(2 \varphi_{j}^{*}-1\right)\right.
\end{array}\right)\right) .
$$

Conditions (24) and (25) cannot be considered independently: since the modified Katz-Bonacich centralities in (24) depend on the voting probabilities, the voting probabilities depend on $s_{\mathbf{A}}$ and $s_{\mathbf{B}}$. The equilibrium monetary transfers and voting probabilities must be found as the joint solution of (24) and (25). As in the previous analysis, however, monetary transfers to legislator $i$ remain proportional to $i$ 's modified Katz-Bonacich centrality. Moreover, as $n \rightarrow \infty$, the codependence between (24) and (25) becomes irrelevant since (by exactly the same argument as in proposition 3) the modified Katz-Bonacich centralities converge to the standard KatzBonacich centralities that are independent of the voting probabilities.

\section{Alternative Objective Functions}

In the analysis presented above, we assume that interest groups maximize the expected number of supporters. This objective function is typically assumed in probabilistic models of electoral competition (see Lindbeck and Weibull 1987). There are, however, environments in which interest groups care about legislators' votes only to the extent that it allows them to reach a given threshold of support (such as a majority). The analysis presented above easily extends to these cases.

To extend the analysis, let us now assume that the interest groups' preferences are represented by a sequence of thresholds $\left(z_{j}, u_{j}\right)_{j=0}^{J}$ for some finite $J$ with $z_{0}=0$ and $u_{0}>0$ and $z_{j}<z_{j+1}$ and $u_{j}<u_{j+1}$ for all $j=$ $0, \ldots, J-1$, such that $A$ 's utility can be written as a step function: $u_{A}\left(\sum_{i} \chi_{i}(p)\right)=u_{j}$ if $\Sigma_{i} \chi_{i}(p) \in\left(z_{j}, z_{j+1}\right]$ for $j \leq J-1$ and $u_{J}$ for $\Sigma_{i} \chi_{i}(p)>z_{J}$. A special example of these preferences is the case in which interest groups care only about obtaining a majority. In this case, the utility is characterized by just one threshold and $z_{1}=(n-1) / 2$ for $n$ odd or $z_{1}=n / 2$ for $n$ even and utility level $u_{1}>u_{0}$. 
Following the same steps as above, it is straightforward to verify that, when legislators are office motivated or when they are policy motivated and there is sufficient uncertainty on their preferences, we have a unique equilibrium in which interest groups offer the same monetary contributions $\mathbf{s}_{A}=\mathbf{s}_{B}=\mathbf{s}_{* *}$. Also, as before, $\mathbf{s}_{* *}$ is characterized as the maximization of a weighted sum of the monetary utilities:

$$
\max _{\mathbf{s} \in S}\left\{\sum_{j} b_{j}^{\mathbf{z}, \mathbf{u}}\left(\phi^{*}, V, G^{T}\right) \cdot \omega_{j}\left(s^{j}\right)\right\},
$$

where $\mathbf{b}^{\mathbf{z}, \mathbf{u}}\left(\phi^{*}, V, G^{T}\right)=\left(b_{j}^{z, \mathbf{u}}\left(\phi^{*}, V, G^{T}\right)\right)_{j=1}^{n}$ are weights that depend on $\phi^{*}, V$, and $G^{T}$ and on the thresholds $\mathbf{z}, \mathbf{u}=\left(z_{j}, u_{j}\right)_{j=0}^{J}$ (a formal derivation of these weights is presented in sec. 5 in the online appendix). The key observation is that the importance of the thresholds vanishes as $n \rightarrow \infty$. Indeed, as we formally prove in section 4 in the online appendix, for any $\mathbf{z}, \mathbf{u}$ we have $b_{i}^{z, \mathbf{u}}\left(\phi^{*}, V, G^{T}\right) \rightarrow \mathbf{b}\left(\phi^{*}, \mathbf{G}^{T}\right)$. In this case, too, therefore, the equilibrium allocation of transfers depends only on the Katz-Bonacich centralities for large $n$.

\section{E. Heterogeneous Policies}

Another assumption we made in the previous analysis is that legislators vote on only one policy. In reality, legislators vote on many policies that could be very different and attract the attention of different sets of interest groups (defense, agriculture, trade, etc.). In these cases, we might have a set $H=\{1, \ldots, h\}$ of different votes, with policy $j=1, \ldots, h$ associated with $N_{j}$ interest groups in favor and $N_{j}$ against, and a per-interest group budget $W_{j}$.

Once again, the analysis is quite similar to the analysis presented above. Assuming preferences as in (17), it is easy to see that in this environment each interest group interested in policy $j \in H$ in Congress $r$ makes a transfer $\mathbf{s}_{r}^{j}=\left(\alpha_{r, j}\right) \cdot b\left(\phi^{*} G_{r}^{T}\right)+X_{r}^{T} \boldsymbol{\xi}_{1}+\boldsymbol{\epsilon}_{r, j}$, and so the total vector of contributions can be estimated as

$$
\mathbf{S}^{r}=\sum_{j} \mathbf{s}_{r}^{j}=\left(\sum_{j} N_{j} \alpha_{r, j}\right) \cdot b\left(\phi^{*} G_{r}^{T}\right)+\left(\sum_{j} N_{j}\right) \cdot X_{r}^{T} \xi_{1}+\epsilon_{r},
$$

that is, proportional to $b\left(\phi^{*} G_{r}^{T}\right)$ as in Section IV.A.

\section{F. Abstention}

In the previous analysis we have assumed that legislators can vote either for $A$ or for $B$, but they cannot abstain. It can be argued, however, that one of the ways in which interest groups exert influence in Congress is by encouraging participation. This may be especially true in a polarized Con- 
gress in which a legislator would never vote for a bill that he does not find "ideologically compatible" (e.g., a gun control bill for a very conservative Republican). There are multiple ways to extend the model presented above to reflect these issues. We propose here an especially simple way. Assume that legislators can be partitioned into two groups. Group $G_{A}$ comprises legislators who would never vote for $B$ : they may vote for $A$ or abstain. Similarly, group $G_{B}$ comprises legislators that would either vote for $B$ or abstain. ${ }^{47}$ A legislator $i$ of type $G_{A}$ would vote for $A$ if

$$
\begin{gathered}
\omega\left(s_{A}^{i}\right)+\phi\left[\sum_{z \in A, B} \eta_{i, z} \sum_{j \in G_{s}} g_{i, j} \chi_{j}\right]+v^{i} q^{i}(\boldsymbol{\varphi}) \\
\geq \omega\left(s_{B}^{i}\right)+\phi\left[\sum_{z \in A, B} \eta_{i, z} \sum_{j \in G_{s}} g_{i, j}\left(1-\chi_{j}\right)\right]+\varepsilon^{i},
\end{gathered}
$$

where $s_{A}^{i}$ and $s_{B}^{i}$ are the contributions received, respectively, from interest group $A$ for voting for $A$ and from interest group $B$ for abstaining. If $j \in G_{A}, \chi_{j}$ is one if $j$ votes for $A$ and zero otherwise; if $j \in G_{B}, \chi_{j}$ is one if $j$ abstains and zero otherwise; $\eta_{i, z}$ for $z=A, B$ are preference parameters; and $\varepsilon^{i}$ is a preference shock, as in the previous analysis. As before, $q^{i}(\varphi)$ is the pivot probability of legislator $i$ as a function of the voting probabilities: now $\varphi_{j}$ is the probability of voting for $A$ for $j \in G_{A}$ and of abstaining if $j \in G_{B}$. In (26), we are assuming that $i \in G_{A}$ likes voting for $A$ (respectively, abstain) more if other connected legislators in $G_{A}$ vote for $A$ (respectively, abstain) and/or other legislators in $G_{B}$ abstain (respectively, vote for $B$ ). In (26), a legislator may value the opinion of other legislators according to their groups: for example, $i \in G_{A}$ is influenced more by other legislators in $G_{A}$ than by other legislators in $G_{B}$ if we assume that $\eta_{A}>\eta_{B}$.

Given (26), the probability $\varphi_{i}$ that $i \in G_{A}$ votes for $A$ is

$$
\boldsymbol{\varphi}_{i}=\frac{1}{2}+\Psi\left(\omega\left(s_{A}^{i}\right)-\omega\left(s_{\varnothing}^{i}\right)+v^{i} q^{i}(\boldsymbol{\varphi})+\phi\left[\sum_{z \in A, B} \eta_{i, z} \sum_{j \in G_{z}} g_{i, j}\left(2 \boldsymbol{\varphi}_{j}-1\right)\right]\right) .
$$

An analogous expression can be derived for an agent $k \in G_{B}$. These characterizations of the voting probabilities can be easily reconstructed to resemble the model described in the previous sections if we modify the network links to incorporate the party affiliations. Let us define $\hat{g}_{i, l}=\eta_{i, A} g_{i, l}$ if $l \in G_{A}$ and $\hat{g}_{i, l}=\eta_{i, B} g_{i, l}$ if $i \in G_{B}$. Then we have

$$
\boldsymbol{\varphi}_{i}=\frac{1}{2}+\Psi\left(\omega\left(s_{A}^{i}\right)-\omega\left(s_{B}^{i}\right)+v^{i} q^{i}(\boldsymbol{\varphi})+\phi\left[\sum_{j} \hat{g}_{i, j}\left(2 \boldsymbol{\varphi}_{j}-1\right)\right]\right),
$$

${ }^{47}$ We could also easily add a group of "nonpartisans" that would vote for $A$ or for $B$, but we ignore this complication for simplicity. 
which is exactly equivalent to (5) when we adopt the network matrix $\hat{G}=$ $\left(\hat{g}_{i, j}\right)_{i, j}$, and we interpret $\varphi_{j}$ as the probability of voting for the alternative associated to $j$ 's types instead of abstaining. Given this, the analysis is exactly equivalent to the analysis presented before and leads to a prediction that monetary transfers are proportional to the legislators' centralities computed using $\hat{G}$.

\section{G. Alternative Network Definitions}

To check for robustness, the last two columns of table 4 collect the NLLS estimations of (19) for alternative network constructions. In column 3, we use a version of the alumni network that is not row-normalized, so the link $g_{i, j}$ between two congressmen $i$ and $j$ is set equal to the number of schools they both attended in overlapping periods. In column 4, the alumni network is enriched with information on party affiliation. More specifically, the intensity of the $i, j$ link is -0.5 if they are not alumni of the same school and belong to a different party; it is 0.5 if they are alumni of the same school but of different parties; it is 0 if they are of the same party but not alumni of the same school; and, finally, it is 1 if $i, j$ attended the same school and are of the same party. This specification reflects the fact that two congressmen from the same party have more opportunities to form a social bond and influence each other and that congressmen of different parties may be penalized. It also allows for negative spillovers between legislators with no social connections and different party affiliations. Table 4 shows that the results of the previous sections are robust to the use of these network definitions. Looking at the RSS, moreover, we see no evidence that these alternative models provide a better fit of the data than the baseline model presented in the previous sections. ${ }^{48}$

\section{Conclusions}

In this paper, we present a new theory of competitive vote buying to study campaign contributions when legislators care about the behavior of other legislators to whom they are socially connected. The theory predicts that campaign contributions are increasing in the legislators' Katz-Bonacich centralities, a standard measure of centrality in networks.

As a first attempt to bring these predictions to the data, we estimate the model with data on PAC contributions in the last five Congresses (the

${ }^{48}$ The RSS of the baseline model is 2,439.94, and the RSSs of the model in cols. 3 and 4 of table 4 are, respectively, 2,488.86 and 2,489.04. Since the three models are not nested and they employ different data sets (i.e., different network constructions), standard measures of the goodness of fit such as the Akaike information criterion are not valid (Burnham and Andreson 2002). The comparisons between the RSSs should therefore be seen as an informal way to compare their fit. 
109th-113th). To measure the legislators' social network and control for endogeneity, we exploit the insight that educational institutions provide a basis for social networks. We therefore construct the social network using the congressmen's alumni connections: two congressmen are connected if they graduated from the same institution within a given time window. This approach provides a network that is exogenous by construction to interest groups' activities. To control for unobserved factors associated with school quality, we include school fixed effects in the regression model. By doing so we exploit variations in network centrality and contributions across alumni of the same school who belong to different cohorts.

As predicted by the theory, legislators' Katz-Bonacich centralities significantly affect campaign contributions. The results are robust to the inclusion of established determinants of PAC contributions used in previous literature. Adding information on the topology of the legislators' social network significantly improves the fit of the model compared with alternative specifications that ignore this information.

We believe there is significant room for further analysis on the impact of legislators' social networks on interest groups' campaign contributions and other influence activities. While our analysis has focused on monetary contributions, it would be interesting to extend the basic theory to situations in which interest groups offer other types of valuable resources, including expertise and contacts with other legislators. It would be particularly interesting to allow the interest groups to affect the network topology by establishing links between legislators, blending our analysis with Ballester et al.'s (2006) analysis of key players. This would improve understanding of the extent to which legislators' social networks affect the activities of lobbyists, who provide campaign contributions, services, and networking resources in the US Congress.

\section{Appendix}

\section{A. Proof of Lemma 1}

The proof for the case with office-motivated legislators is presented in Section III.A. For the case with policy-motivated legislators, see the online appendix.

\section{B. Proof of Propositions 1 and 2}

We prove the result for general $v=\left(v^{1}, \ldots, v^{n}\right)$. This allows us to prove proposition 2 and then proposition 1 as a special case of proposition 2. Following the same steps as in Section III.B.1, we can derive

$$
D_{i}[\boldsymbol{\varphi}]=\Psi\left(I-\Psi\left(V \cdot D \mathbf{q}_{*}+2 \phi G\right)\right)^{-1} \cdot D_{i}[\boldsymbol{\omega}],
$$

where $V$ is the $n$-dimensional diagonal matrix with $i$ th diagonal entry equal to $v^{i}$, and $D \mathbf{q}_{*}$ is the $n$-dimensional matrix with generic $i, j$ element equal to $q_{j}^{i}$ as defined 
in Section III.B.2. The first-order necessary and sufficient condition of the problem solved by interest group $l$ can be written in matrix form as $D_{i}[\boldsymbol{\varphi}]^{T} \cdot \mathbf{1}=\lambda_{l}$, where $\lambda_{l}$ is the Lagrangian multiplier of interest group $l$ 's program. Using (A1), we have

$$
\begin{aligned}
D_{i}[\boldsymbol{\varphi}]^{T} \cdot \mathbf{1} & =\left[\Psi(I-\Psi(V \cdot D \mathbf{q}+2 \phi G))^{-1} \cdot D_{i}[\boldsymbol{\omega}]\right]^{T} \cdot \mathbf{1} \\
& =\Psi \cdot D_{i}[\boldsymbol{\omega}]^{T}\left(I-\left(\phi^{*} G^{T}+\Psi D \mathbf{q}_{*}^{T} V\right)\right)^{-1} \cdot \mathbf{1}=\lambda_{l} \\
& \Rightarrow D_{i}[\boldsymbol{\omega}]^{T} \cdot \mathbf{b}^{\mathcal{M}}\left(\phi^{*}, V, G^{T}\right)=\lambda_{l} / \Psi
\end{aligned}
$$

for $l=A, B$, where for the last equality we used (15) and $\phi^{*}=2 \phi \Psi$. Note that $D_{i}[\omega]$ is a vector of zeros except for its $i$ th element, which is equal to $\omega^{\prime}\left(s_{*}^{i}\right)$. We can therefore write our necessary and sufficient conditions (10) as

$$
\begin{aligned}
& b_{i}^{\mathcal{M}}\left(\phi^{*}, V, G^{T}\right) \cdot \omega^{\prime}\left(s_{A}^{i}\right)=\lambda_{A}, \\
& b_{i}^{\mathcal{M}}\left(\phi^{*}, V, G^{T}\right) \cdot \omega^{\prime}\left(s_{B}^{i}\right)=\lambda_{B},
\end{aligned}
$$

where, without loss of generality, we have incorporated the constant $\Psi$ in the Lagrangian multipliers. If $\lambda_{A}>\lambda_{B}$ (respectively, $\lambda_{A}<\lambda_{B}$ ), then by (10) we would have

$$
\omega^{\prime}\left(s_{A}^{i}\right)=\lambda_{A} / b_{i}^{\mathcal{M}}\left(\phi^{*}, V, G^{T}\right)<\lambda_{B} / b_{i}^{\mathcal{M}}\left(\phi^{*}, V, G^{T}\right)=\omega^{\prime}\left(s_{B}^{i}\right),
$$

implying $\omega^{\prime}\left(s_{A}^{i}\right)>\omega^{\prime}\left(s_{B}^{i}\right)$ (respectively, $\left.\omega^{\prime}\left(s_{A}^{i}\right)<\omega^{\prime}\left(s_{B}^{i}\right)\right)$ for any $i$, and so $\sum s_{B}^{i}>\sum s_{A}^{i}=$ $W$ (respectively, $\Sigma s_{A}^{i}>\sum s_{B}^{i}=W$ ), a contradiction. We conclude that $\lambda_{A}=\lambda_{B}=\lambda_{*}$ for some $\lambda_{*}>0$, implying that there is a unique solution $\left(\lambda_{*}, \mathbf{S}_{*}\right)$ such that $\lambda_{i}=\lambda_{*}$ and $\mathbf{s}_{i}=\mathbf{s}_{*}$ for $i=A, B$. QED

\section{Proof of Proposition 3}

Let $\iota(\cdot)$ be a function that maps agents to their respective groups and let $H$ be the $m \times m$ matrix describing the relationships between the types, so that $g_{i j}=h_{\iota(i), t(j)}$. We start with two preliminary results. The first result shows that, when we have a finite number of types, the Katz-Bonacich centralities are well-defined functions of only the shares of the types $\alpha$ and of the matrix $H$ describing the relationships between the types. We have the following lemma:

Lemma 3.1. For any $i=1, \ldots, n, b^{i}\left(\phi^{*}, G^{T}\right)$ is equal to $\bar{b}_{\iota(i)}(H, \boldsymbol{\alpha})$ defined by

$$
\overline{\mathbf{b}}(H, \boldsymbol{\alpha})=\left[I+\phi^{*} \tilde{H}^{T}\right]^{-1} \cdot \mathbf{1},
$$

where $\overline{\mathbf{b}}(H, \boldsymbol{\alpha})=\left(\bar{b}_{1}(H, \boldsymbol{\alpha}), \ldots, \bar{b}_{m}(H, \boldsymbol{\alpha})\right)^{T}$ and $\tilde{H}$ is the $m \times m$ matrix with element $i, j$ equal to $\tilde{h}_{i, j}=\alpha_{i} h_{i, j} /\left(\sum_{l} h_{i, l}\right)$.

Proof. See the online appendix.

Note that $\tilde{H}$ is an $m \times m$ matrix with bounded elements since $\tilde{h}_{i, j} \leq \sum_{i} \tilde{h}_{i, j} \leq$ $\sum_{i} g_{i, j} \leq \bar{g}$.

The second preliminary result shows that as $n \rightarrow \infty$, the equilibrium pivot probabilities and the sum of their derivatives converge to zero. For a sequence of equilibria $\left(\varphi_{l}^{n}\right)_{l}$, let $q_{n}^{i}$ be the associated pivot probability of legislator $i$ and $q_{n, j}^{i}$ be the derivative of $q_{n}^{i}$ with respect to $\varphi_{j}^{n}$. We have the following lemma:

Lemma 3.2. $\lim _{n \rightarrow \infty} q_{n}^{i}=0, \lim _{n \rightarrow \infty} \sum_{j=1}^{n}\left|q_{n, j}^{i}\right|=0$, for any $i, j$. 
Proof. See the online appendix.

To complete the proof, consider a sequence of populations of size $n \rightarrow \infty$ in which the network is $G_{n}$ and the share of type $j$ is $\alpha_{n}^{j} \rightarrow \alpha^{j}$. We need to show that $b_{i}^{\mathcal{M}}\left(\phi^{*}, V, G_{n}^{T}\right) \rightarrow \bar{b}_{\iota(i)}(H, \alpha)$ for all $i$ as $n \rightarrow \infty$. To keep the notation simple, let $\tilde{b}_{j}^{n}$ be the modified Katz-Bonacich of an agent of type $j$. We can write

$$
\tilde{b}_{\iota(i)}^{n}=1+\phi \sum_{l=1}^{m} \tilde{h}_{l, l(i)}^{n} \tilde{b}_{l}^{n}+v_{\iota(i)} \sum_{l=1}^{m} n_{l} \tilde{q}_{n, l}^{(i)} \tilde{b}_{l}^{n},
$$

where $\tilde{h}_{i, j}=n_{i} h_{i, j}$ and $\tilde{q}_{n, l}^{\ell(i)}$ is the derivative of the pivot probability of an agent of type $\iota(i)$ with respect to the voting probability of a type $l$. Note that $\left|n_{l} \tilde{q}_{n, l}^{(i)}\right| \leq$ $\sum_{j=1}^{n}\left|q_{n, j}^{i}\right|$ and, by lemma 3.2, $\sum_{j=1}^{n}\left|q_{n, j}^{i}\right| \rightarrow 0$ as $n \rightarrow \infty$. It follows that we can write $\tilde{\mathbf{b}}^{n}=\Psi \cdot\left[I+\phi^{*}\left[\tilde{H}^{n}\right]^{T}+O(n)\right]^{-1} \cdot \mathbf{1}$, where $\tilde{\mathbf{b}}^{n}=\left(\tilde{b}_{1}^{n}, \ldots, \tilde{b}_{m}^{n}\right)^{T}, \tilde{H}^{n}$ is the $m \times m$ matrix with element $i$, jequal to $\tilde{h}_{i, j}=n_{i} h_{i, j}$, and $O(n)$ is an $m \times m$ matrix with all terms converging to zero as $n \rightarrow \infty$. Note that $\tilde{h}_{i, j} \leq \sum_{i=1}^{m} n_{i} h_{i, j}=\sum_{l=1}^{n} g_{l, j} \leq \bar{g}$, so $\tilde{H}^{n}$ converges to a positive and bounded $m \times m$ matrix $\tilde{H}$. Taking the limit as $n \rightarrow \infty$, we obtain $\lim _{n \rightarrow \infty} \tilde{\mathbf{b}}^{n}=\Psi\left[I+\phi^{*} \tilde{H}^{T}\right]^{-1} \cdot \mathbf{1}$. It follows that $b_{i}^{\mathcal{M}}\left(\phi^{*}, V\right.$, $\left.G_{n}^{T}\right) \rightarrow \bar{b}_{\imath(i)}(H, \boldsymbol{\alpha})$ for all $i$ as $n \rightarrow \infty$ as requested. QED

D. Additional Tables

TABLE A1

Summary Statistics $(\mathrm{N}=2,125)$

\begin{tabular}{|c|c|c|c|}
\hline & Variable Definition & Mean & $\begin{array}{l}\text { Standard } \\
\text { Deviation }\end{array}$ \\
\hline $\begin{array}{l}\text { PAC contributions } \\
\text { (\$millions) }\end{array}$ & $\begin{array}{l}\text { PAC contributions to a member of Congress; } \\
\text { source: http://opensecrets.org. }\end{array}$ & 922,104 & $1,092.194$ \\
\hline Party & $\begin{array}{l}\text { Dummy variable taking a value of } 1 \text { if the } \\
\text { congressman is a Democrat }\end{array}$ & .508 & .500 \\
\hline Gender & $\begin{array}{l}\text { Dummy variable taking a value of } 1 \text { if the } \\
\text { congressman is female }\end{array}$ & .174 & .379 \\
\hline Chair & $\begin{array}{l}\text { Dummy variable taking a value of } 1 \text { if the } \\
\text { congressman is a chair of at least one } \\
\text { committee }\end{array}$ & .046 & .209 \\
\hline Seniority & $\begin{array}{l}\text { Maximum consecutive years in the same } \\
\text { committee }\end{array}$ & 7.549 & 6.241 \\
\hline Margin of victory & $\begin{array}{l}\text { Dummy variable taking a value of } 1 \text { if the } \\
\text { election margin of victory is less than } 5 \%\end{array}$ & .050 & .218 \\
\hline Majority party & $\begin{array}{l}\text { Dummy variable taking a value of } 1 \text { if the } \\
\text { congressman is a member of the majority } \\
\text { party in the House of Representatives }\end{array}$ & .553 & .497 \\
\hline DW ideology & $\begin{array}{l}\text { Distance to the center in terms of ideology } \\
\text { measured using the absolute value of the } \\
\text { first dimension of the DW-Nominate score } \\
\text { created by McCarty et al. (1997) }\end{array}$ & .502 & .221 \\
\hline Relevant committee & $\begin{array}{l}\text { Dummy variable taking a value of } 1 \text { if the } \\
\text { congressman is a member of a powerful } \\
\text { committee (Appropriations, Budget, } \\
\text { Rules, and Ways and Means) }\end{array}$ & .386 & .486 \\
\hline Unconnected & $\begin{array}{l}\text { Dummy variable taking a value of } 1 \text { if the } \\
\text { congressman did not graduate from the } \\
\text { same institution within } 4 \text { years with any } \\
\text { other congressman }\end{array}$ & .640 & .480 \\
\hline
\end{tabular}




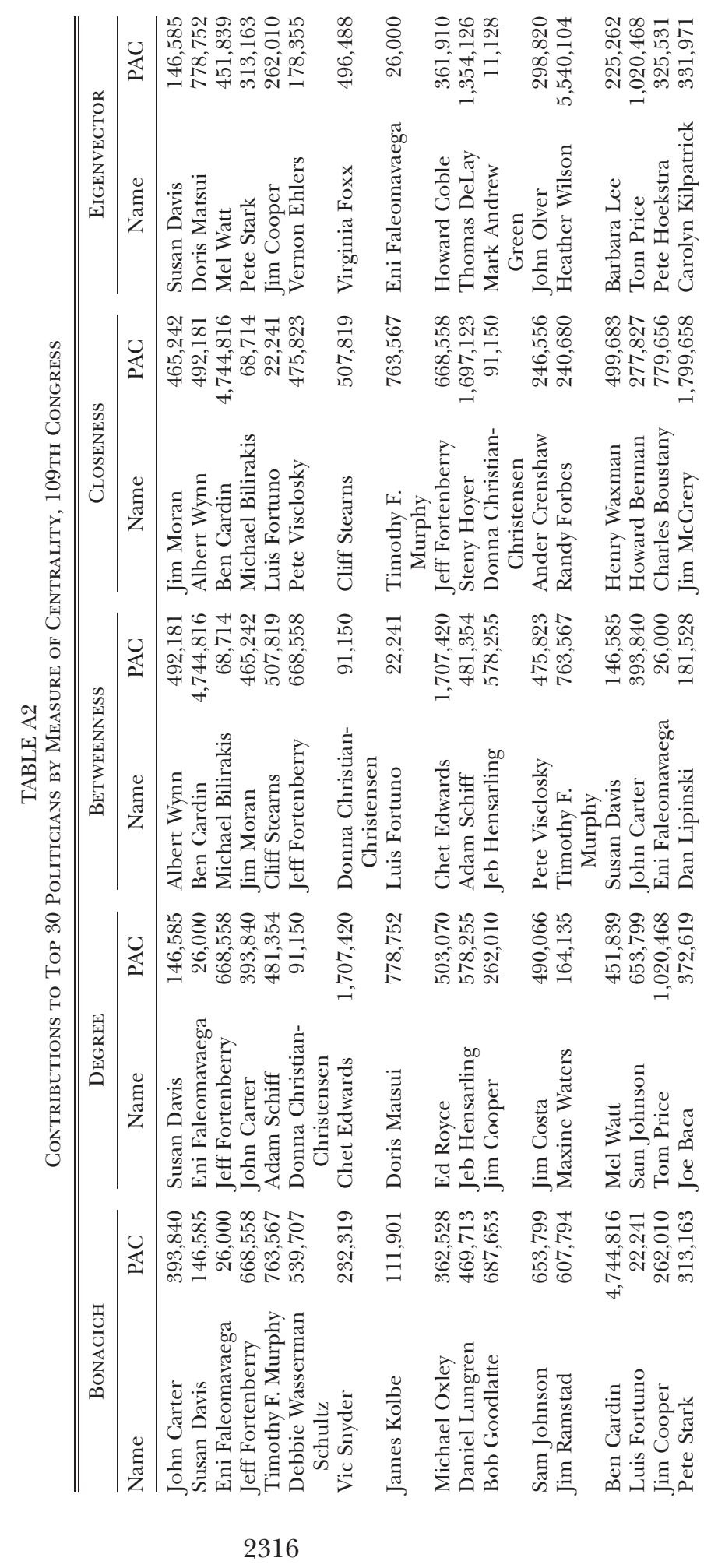




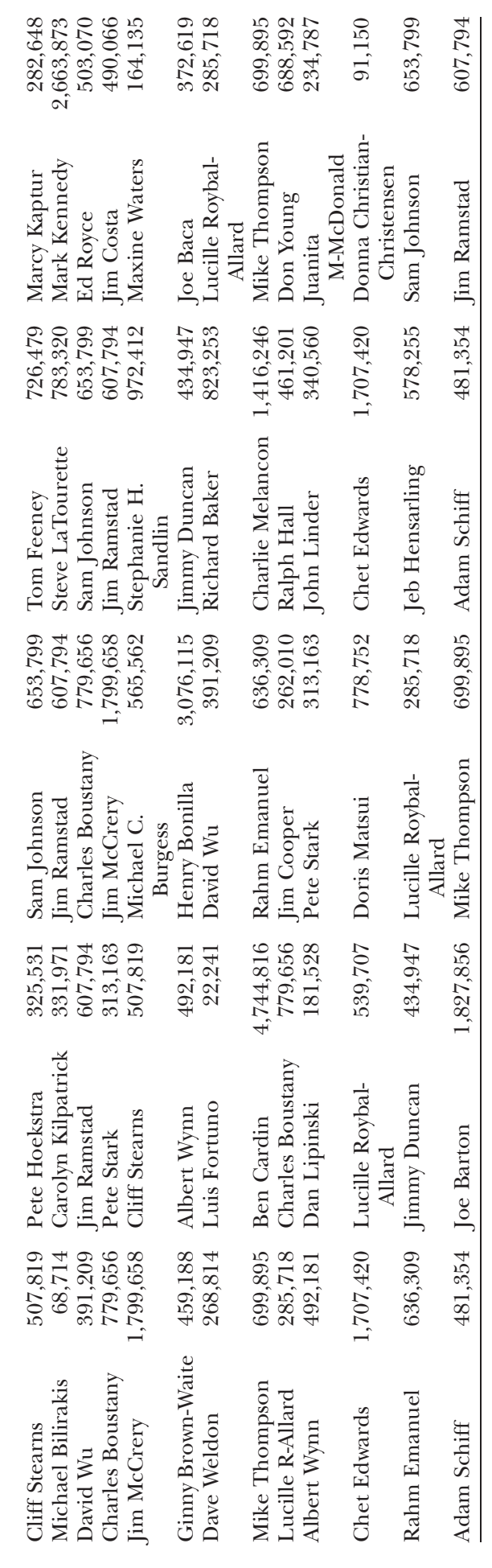


References

Akerlof, George. 1980. "A Theory of Social Custom, of Which Unemployment May Be One Consequence.” Q.J.E. 94:749-75.

Anderson, Gary M., and Robert D. Tollison. 1990. "Democracy in the Marketplace." In Predicting Politics, edited by W. Mark Crain and Robert D. Tollison. Ann Arbor: Univ. Michigan Press.

Ansolabehere, Stephen D., John M. de Figueiredo, and James M. Snyder Jr. 2003. "Why Is There So Little Money in U.S. Politics?" J. Econ. Perspectives 17 (1): 10530 .

Ansolabehere, Stephen D., and James M. Snyder Jr. 1999. "Money and Institutional Power." Texas Law Rev. 77:1673-1704.

Arnold, Laura W., Rebecca E. Deen, and Samuel C. Patterson. 2000. "Friendship and Votes: The Impact of Interpersonal Ties on Legislative Decision Making." State and Local Government Rev. 32 (2): 142-47.

Asch, Solomon E. 1951. "Effects of Group Pressure upon the Modification and Distortion of Judgments." In Groups, Leadership and Men, edited by H. Guetzkow. Pittsburgh: Carnegie Press.

Austen-Smith, David. 1992. "Strategic Models of Talk in Political Decision Making.” Internat. Polit. Sci. Rev. 13 (1): 45-58.

. 1995. "Campaign Contributions and Access." American Polit. Sci. Rev. 89 (3): 566-81.

Austen-Smith, David, and John R. Wright. 1992. "Competitive Lobbying for a Legislator's Vote.” Soc. Choice and Welfare 9 (3): 229-57.

Bailey, Stephen K., and Howard D. Samuel. 1952. Congress at Work. New York: Holt.

Baker, Ross K. 1980. Friend and Foe in the U.S. Senate. New York: Free Press/Collier Macmillan.

Ballester, Coralio, Antoni Calvó-Armengol, and Yves Zenou. 2006. "Who's Who in Networks. Wanted: The Key Player.” Econometrica 74 (5): 1403-17.

Banks, Jeffrey S. 2000. "Buying Supermajorities in Finite Legislatures." American Polit. Sci. Rev. 94 (3): 677-81.

Baron, David P. 2006. "Competitive Lobbying and Supermajorities in a MajorityRule Institution.” Scandinavian J. Econ. 108 (4): 607-42.

Becker, Gary. 1991. "A Note on Restaurant Pricing and Other Examples of Social Influences on Price.” J.P.E. 99 (5): 1109-16.

Becker, Gary, and Kevin M. Murphy. 2001. Social Economics. Cambridge, MA: Harvard Univ. Press.

Bennedsen, Morten, and Sven E. Feldmann. 2002. "Lobbying Legislatures.” J.P.E. 110 (4): 919-46.

Bernheim, B. Douglas. 1994. “A Theory of Conformity.” J.P.E. 102 (5): 841-77.

Bertrand, Marianne, Matilde Bombardini, and Francesco Trebbi. 2014. "Is It Whom You Know or What You Know? An Empirical Assessment of the Lobbying Process." A.E.R. 104 (12): 3885-3920.

Besley, Timothy, and Stephen Coate. 2001. "Lobbying and Welfare in a Representative Democracy." Rev. Econ. Studies 68 (1): 67-82.

Bharathi, Shishir, David Kempe, and Mahyar Salek. 2007. "Competitive Influence Maximization in Social Networks." In Internet and Network Economics, edited by X. Deng and F. C. Graham, 306-11. Lecture Notes in Computer Science, 4858. Berlin: Springer.

Blanes i Vidal, Jordi, Mirko Draca, and Christian Fons-Rosen. 2012. "Revolving Door Lobbyists." A.E.R. 102 (7): 3731-48. 
Bonacich, Phillip. 1987. "Power and Centrality: A Family of Measures." American J. Sociology 92 (5): 1170-82.

Bramoulle, Yann, Rachel Kranton, and Martin D'Amours. 2014. "Strategic Interaction and Networks." A.E.R. 104 (3): 898-930.

Brock, William A., and Steven N. Durlauf. 2001. "Discrete Choice with Social Interactions." Rev. Econ. Studies 68 (2): 235-60.

Buchanan, James M., and Gordon Tullock. 1962. The Calculus of Consent. Ann Arbor: Univ. Michigan Press.

Burnham, Kenneth P., and David R. Andreson. 2002. Model Selection and Multimodel Inference. 2nd ed. New York: Springer.

Caldeira, Gregory A., John A. Clark, and Samuel C. Patterson. 1993. "Political Respect in the Legislature." Legislative Studies Q. 18 (1): 3-28.

Caldeira, Gregory A., and Samuel C. Patterson. 1987. "Political Friendship in the Legislature." J. Politics 49 (4): 953-75.

Calvert, Randall L. 1985. "Robustness of the Multidimensional Voting Model: Candidate Motivations, Uncertainty, and Convergence." American J. Polit. Sci. 29 (1): 69-95.

Calvó-Armengol, Antoni, Eleonora Patacchini, and Yves Zenou. 2009. "Peer Effects and Social Networks in Education." Rev. Econ. Studies 76 (4): 1239-67.

Canen, Nathan, and Francesco Trebbi. 2016. "Endogenous Network Formation in Congress." Manuscript, Vancouver School Econ.

Cho, Wendy K. T., and James H. Fowler. 2010. "Legislative Success in a Small World: Social Network Analysis and the Dynamics of Congressional Legislation." J. Politics 72 (1): 124-35.

Clapp, Charles L. 1963. The Congressman: His Work as He Sees It. Washington, DC: Brookings Inst.

Cohen, Lauren, Andrea Frazzini, and Christopher Malloy. 2008. "The Small World of Investing: Board Connections and Mutual Fund Returns." J.P.E. 116 (5): 95179.

Cohen, Lauren, and Christopher Malloy. 2014. "Friends in High Places." American Econ. J.: Econ. Policy 6 (3): 63-91.

Cotton, Christopher S. 2012. "Pay to Play Politics: Informational Lobbying and Contribution Limits When Money Buys Access." J. Public Econ. 96:369-86.

Dal Bo, Ernesto. 2007. "Bribing Voters." American J. Polit. Sci. 51 (4): 789-803.

de Figueiredo, John M., and Brian K. Richter. 2014. "Advancing the Empirical Research on Lobbying." Ann. Rev. Polit. Sci. 17:163-85.

Dekel, Eddie, Matthew O. Jackson, and Asher Wolinsky. 2008. "Vote Buying: General Elections." J.P.E. 116 (2): 351-80.

. 2009. "Vote Buying: Legislatures and Lobbying," Q. J. Polit. Sci. 4 (2): 103-28.

Denzau, Arthur T., and Michael Munger. 1986. "Legislators and Interest Groups." American Polit. Sci. Rev. 80 (1): 89-106.

Deutsch, Morton, and Harold B. Gerard. 1955. "A Study of Normative and Informational Social Influences upon Individual Judgment." J. Abnormal and Soc. Psychology 51 (3): 629-36.

Diermeier, Daniel, and Roger B. Myerson. 1999. "Bicameralism and Its Consequences for the Internal Organization of Legislatures.” A.E.R. 89 (5): 1182-96.

Dixit, Avinash. 1996. "Special Interest Lobbying and Endogenous Commodity Taxation." Eastern Econ. J. 22 (4): 375-88.

Dixit, Avinash, Gene M. Grossman, and Elhanan Helpman. 1997. "Common Agency and Coordination: General Theory and Application to Government Policy Making." J.P.E. 105:752-69. 
Do, Q., Yen-Teik Lee, and Bang Dang Nguyen. 2016. "Directors as Connectors: The Impact of the External Networks of Directors on Firms." Manuscript, Paris School Econ.

Domingos, Pedro, and Matthew Richardson. 2001. "Mining the Network Value of Customers." In Proceedings of the Seventh International Conference on Knowledge Discovery and Data Mining, 57-66. San Francisco: ACM Press.

Eulau, Heinz. 1962. Class and Party in the Eisenhower Years. New York: Free Press.

Fowler, James H. 2006. "Connecting the Congress: A Study of Cosponsorship Networks.” Polit. Analysis 14 (4): 456-87.

Fracassi, Cesare, and Geoffrey Tate. 2012. "External Networking and Internal Firm Governance." J. Finance 67 (1): 153-94.

Glaeser, Edward L., Bruce Sacerdote, and Jose Scheinkman. 1996. "Crime and Social Interactions." Q.J.E. 111 (2): 507-48.

Grier, Kevin B., and Michael C. Munger. 1986. "The Impact of Legislator Attributes on Interest-Group Campaign Contributions.” J. Labor Res. 7:349-61.

_ 1991. "Committee Assignments, Constituent Preferences, and Campaign Contributions." Econ. Inquiry 29 (1): 24-43.

_. 1993. "Comparing Interest Group PAC Contributions to House and Senate Incumbents, 1980-1986.” J. Politics 55 (3): 615-43.

Groenert, V. 2010. "Strategic Equilibrium in Social Networks and Games: Theory and Applications." Manuscript, Vanderbilt Univ.

Groll, Thomas, and Anja Prummer. 2016. "Whom to Lobby? Targeting in Political Networks." Manuscript, Cambridge-Inst. New Econ. Thinking.

Groseclose, Tim, and James M. Snyder. 1996. "Buying Supermajorities." American Polit. Sci. Rev. 90:303-15.

Grossman, Gene M., and Elhanan Helpman. 1994. "Protection for Sale." A.E.R. 84 (4): 833-50.

-2001. Special Interest Politics. Cambridge, MA: MIT Press.

Harmon, Nikolaj, Raymond Fisman, and Emir Kamenica. 2018. "Peer Effects in Legislative Voting.” Working Paper no. dp-304, Dept. Econ., Boston Univ.

Helpman, Elhanan, and Torsten Persson. 2001. "Lobbying and Legislative Bargaining." Advances Econ. Analysis and Policy 11:art. 3.

Jackson, Matthew O. 2008. Social and Economic Networks. Princeton, NJ: Princeton Univ. Press.

Jones, Stephen R. G. 1984. The Economics of Conformism. Oxford: Blackwell.

Kamada, Tomihisa, and Satoru Kawai. 1989. "An Algorithm for Drawing General Undirected Graphs." Information Processing Letters 31 (1): 7-15.

Kang, Karam. 2015. "Policy Influence and Private Returns from Lobbying in the Energy Sector." Rev. Econ. Studies 83 (1): 269-305.

Kang, Karam, and Hye Young You. 2017. "The Value of Connections in Lobbying." Manuscript, Carnegie Mellon Univ.

Kempe, David, Jon Kleinberg, and Eva Tardos. 2005. "Influential Nodes in a Diffusion Model for Social Networks." In Automata, Languages and Programming: ICALP 2005, edited by L. Caires, G. F. Italiano, L. Monteiro, C. Palamidessi, and M. Yung. Lecture Notes in Computer Science, vol. 3580. Berlin, Heidelberg: Springer.

- 2015. "Maximizing the Spread of Influence through a Social Network." Theory of Computing 11:105-47.

Lever, Carlos R. 2010. "Strategic Spending in Voting Competitions with Social Networks." Working Paper no. 2010-16, Banco de Mexico.

Lindbeck, Assar, and Jorgen Weibull. 1987. "Balanced-Budget Redistribution as the Outcome of Political Competition." Public Choice 52:273-97. 
Masket, Seth E. 2008. "Where You Sit Is Where You Stand: The Impact of Seating Proximity on Legislative Cue-Taking." Q. J. Polit. Sci. 3:301-11.

Matthews, Donal R., and James A. Stimson. 1975. Yeas and Nays: Normal DecisionMaking in the U.S. House of Representatives. New York: Wiley.

McCarty, Nolan, Keith T. Poole, and Howard Rosenthal. 1997. Income Redistribution and the Realignment of American Politics. Washington, DC: AEI Press.

Monsma, Stephen V. 1966. "Interpersonal Relations in the Legislative System: A Study of the 1964 Michigan House of Representatives." Midwest J. Polit. Sci. 10 (3): 350-63.

Nokken, Timothy P., and Keith T. Poole. 2004. "Congressional Party Defection in American History." Legislative Studies Q. 29:545-68.

Patterson, Samuel C. 1959. "Patterns of Interpersonal Relations in a State Legislative Group: The Wisconsin Assembly." Public Opinion Q. 23 (1): 101-9.

Persson, Torsten. 1998. "Economic Policy and Special Interest Politics." Econ. J. 108 (447): 310-27.

Piketty, Thomas. 1994. "Information Aggregation through Voting and Vote Trading." Manuscript, Paris School Econ.

Poole, Keith T., and Thomas Romer. 1985. "Patterns of Political Action Committee Contributions to the 1980 Campaigns for the U.S. House of Representatives." Public Choice 47 (1): 63-112.

Poole, Keith T., Thomas Romer, and Howard Rosenthal. 1987. "The Revealed Preferences of Political Action Committees." A.E.R. Papers and Proc. 77:298-302.

Poole, Keith T., and Howard Rosenthal. 1997. Congress: A Political-Economic History of Roll Call Voting. New York: Oxford Univ. Press.

Porter, Mason A., Peter J. Mucha, Mark E. J. Newman, and Casey M. Warmbrand. 2005. "A Network Analysis of Committees in the U.S. House of Representatives.” Proc. Nat. Acad. Sci. 102 (20): 7057-62.

Rice, Stuart A. 1927. "The Identification of Blocs in Small Political Bodies." American Polit. Sci. Rev. 21 (3): 619-27.

-1928. Quantitative Methods in Politics. New York: Knopf.

Richardson, Matthew, and Pedro Domingos. 2002. "Mining Knowledge-Sharing Sites for Viral Marketing." In Proceedings of the Eighth International Conference on Knowledge Discovery and Data Mining, 61-70. Edmonton, Canada: ACM Press.

Ringe, Nils, Jennifer N. Victor, and Justin H. Gross. 2013. "Keeping Your Friends Close and Your Enemies Closer? Information Networks in Legislative Politics." British J. Polit. Sci. 43 (3): 601-28.

Romer, Thomas, and James M. Snyder Jr. 1994. "An Empirical Investigation of the Dynamics of PAC Contributions." American J. Polit. Sci. 38 (3): 745-69.

Ross, Lee, Günter Bierbrauer, and Susan Hoffman. 1976. "The Role of Attribution Processes in Conformity and Dissent: Revisiting the Asch Situation." American Psychologist 31:148-57.

Routt, Garland C. 1938. "Interpersonal Relationships and the Legislative Process." Ann. American Acad. Polit. and Soc. Sci. 195:129-36.

Schelling, Thomas C. 1973. "Hockey Helmets, Concealed Weapons, and Daylight Saving.” J. Conflict Resolution 17 (3): 381-428.

Snyder, James M., Jr. 1990. "Campaign Contributions as Investments: The House of Representatives, 1980-1986.” J.P.E. 98 (6): 1195-1227.

-. 1991. "On Buying Legislatures." Econ. and Politics 3 (2): 93-109.

Stigler, George. 1971. "The Theory of Economic Regulation." Bell J. Econ. and Management Sci. 2:3-21.

Stratmann, Thomas. 1992. "Are Contributors Rational? Untangling Strategies of Political Action Committees.” J.P.E. 100 (3): 647-64. 
. 2005. "Some Talk: Money in Politics. A (Partial) Review of the Literature." Public Choice 124:135-56.

Truman, David B. 1951. The Governmental Process: Political Interests and Public Opinion. New York: Knopf.

Zenou, Yves. 2015. "Networks in Economics." In International Encyclopedia of the Social and Behavioral Sciences, 2nd ed., edited by J. D. Wright, 572-81. Amsterdam: Elsevier.

Zhang, Yan, A. J. Friend, Amanda L. Traud, Mason A. Porter, James H. Fowler, and Peter J. Mucha. 2008. "Community Structure in Congressional Cosponsorship Networks.” Physica A 387 (7): 1705-12. 